\title{
Diketopyrrolopyrrole Derivatives Functionalized with N-Annulated PDI and Se-Annulated PDI by Direct (Hetero)Arylation Methods
}

\author{
Thomas A. Welsh, Maryam Nazari, and Gregory C. Welch* \\ Department of Chemistry, University of Calgary \\ 2500 University Drive NW Calgary, AB, Canada T2N 1 N4. \\ *Corresponding Authors \\ Email: gregory.welch@ucalgary.ca \\ Phone Number: 1-403-210-7603
}

Supporting Information (SI): Experimental details. Details on cyclic voltammetry, optical absorption and emission spectroscopy, and atomic force microscopy.

\begin{abstract}
We report on the synthesis of diketopyrrolopyrrole (DPP) derivatives functionalized with $\mathrm{N}$ annulated and Se-annulated perylene diimide (NPDI and SePDI, respectively) via direct (hetero)arylation methods. DPP is symmetrically bifunctionalized with SePDI (SePDI-DPPSePDI) and unsymmetrically functionalized with SePDI and NPDI (SePDI-DPP-NPDI). The effects of Se substitution compared to $\mathrm{N}$ substitution on physical, electrochemical, and optical properties are investigated along with performance as non-fullerene acceptors in photovoltaic devices. It is found that Se substitution increases the electron affinity of the $\pi$-conjugated molecule and blue shifts the optical absorption spectra, observations that were supported by computational analysis. Steric strain between the PDI endcap and DPP core prevent complete electronic communication along the $\pi$-conjugated backbone and results in the unsymmetrical compound, SePDI-DPP-NPDI, having electronic and optical properties that are a linear combination of both
\end{abstract}


the symmetrical SePDI and NPDI based compounds. Different is that the SePDI-DPP-NPDI compound has a distinct melt observed at $343{ }^{\circ} \mathrm{C}$ and organic photovoltaic devices based on this compound had lower than expected open-circuit voltages, suggesting a unique solid-state packing arrangement. SePDI-based compounds performed worse than the NPDI-based compound in organic photovoltaic devices using the donor polymer PTB7-Th. 


\section{Introduction}

The synthesis of $\pi$-conjugated organic functional materials is of great importance in the development of new optoelectronic technology. ${ }^{1}$ Organic materials are attractive since they can be derived from abundant and/or renewable feedstocks, have tuneable physical and optoelectronic properties via structural modification, and can easily be processed into uniform electronically active films from solution. As such organic materials have found utility as semiconductors in solar cells, ${ }^{2-5}$ field-effect transistors, ${ }^{6-8}$ and light-emitting devices. ${ }^{9-11}$

Our research team has been developing organic materials based on the versatile perylene diimide (PDI) chromophore for use as non-fullerene acceptors (NFA) in solution processed organic photovoltaic (OPV) devices. ${ }^{12}$ One of the most effective materials developed, NPDI-DPPNPDI (Figure 1), is comprised of a diketopyrrolopyrrole (DPP) core flanked by N-annulated PDI endcaps. ${ }^{13}$ This material is readily synthesized on multi-gram scale using direct (hetero)arylation (DHA) methods, exhibits strong visible light absorption, and has relatively higher lying frontier molecular orbital energy levels compared to related PDI materials enabling the fabrication of OPV devices with open circuit voltages $\left(V_{O C}\right)$ greater than $1 \mathrm{~V}$. Linear aliphatic side-chains on the DPP core direct the self-assembly of this molecule upon solvent vapour annealing, ${ }^{14}$ in the presence of donor polymers, leading to crystallization of thin-films and enhanced photovoltaic performance, ${ }^{15}$ and thus has been used as a universal NFA. ${ }^{16-18}$

The material NPDI-DPP-NPDI incorporates the N-annulated PDI chromophore, ${ }^{19}$ for which the pyrrolic N-position adds an extra site for side-chain engineering to alter solubility and self-assembly and lowers the molecules electron affinity. ${ }^{20,21}$ The brominated $\mathrm{N}$-annulated PDI has proved quite effective for use as a substrate in DHA cross-coupling reactions, where symmetrical, ${ }^{22,23}$ unsymmetrical, ${ }^{24,25}$ and tetrameric ${ }^{26,27}$ molecules have been readily constructed. 
The PDI chromophore can also be annulated at the bay position with Se (SePDI) which can improve intermolecular interactions between PDI molecules, and as such, NFAs have been constructed using the SePDI building block and have led to increased OPV performance. For example, the SePDI dimer, (SePDI)2, is an effective NFA for polymer based OPVs leading to high PCEs of $8.4 \% .^{28,29}$ SePDI has also been incorporated into trimeric ${ }^{30,31}$ and tetrameric ${ }^{32}$ NFAs leading to OPVs with PCEs ranging from 8-9\%.

As an extension to our work investigating the NPDI-DPP-NPDI NFA, we aimed to systematically replace the NPDI unit with the SePDI unit. Herein, we report on the synthesis of two new DPP-based molecular $\pi$-conjugated materials incorporating the SePDI unit abbreviated as SePDI-DPP-NPDI and SePDI-DPP-SePDI (Figure 1). Both materials were synthesized using DHA methods. ${ }^{13}$ It is worthwhile to mention that the SePDI required the use of larger pentylhexyl (C11) sidechains at the imide positions to solubilize both the SePDI unit and the final materials, ${ }^{29}$ whereas the NPDI with the extra site for side chain attachment is readily solubilized using the shorter ethylpropyl (C5) sidechains ${ }^{13}$ (Figure 1).

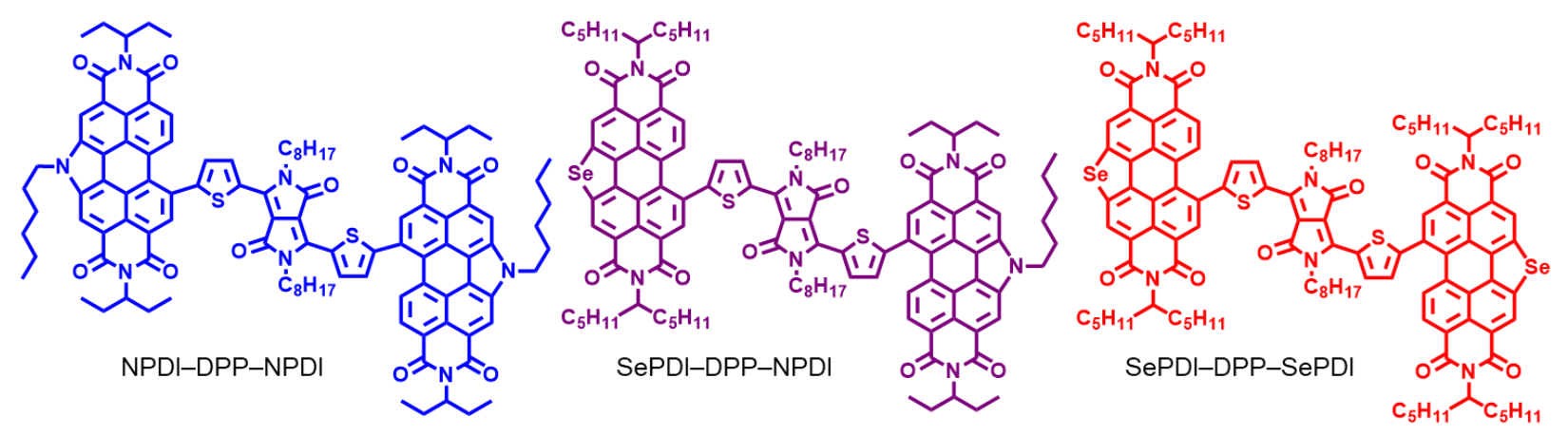

Figure 1. The molecular structures of the know compound NPDI-DPP-NPDI, ${ }^{13}$ and the new compounds SePDI-DPP-NPDI and SePDI-DPP-SePDI. 


\section{Synthesis}

Compounds SePDI-DPP-NPDI and SePDI-DPP-SePDI were synthesized following our groups standard DHA cross-coupling conditions to yield symmetrical and unsymmetrical DPPbased molecules. $^{24,25}$ Using these conditions, coupling the brominated SePDI with DPP produced a mixture of monosubstituted SePDI-DPP and disubstituted SePDI-DPP-SePDI in an approximately 1:2 ratio, determined by ${ }^{1} \mathrm{H}$ NMR spectroscopic analysis. The compounds were separated via column chromatography with SePDI-DPP-SePDI being obtained in a final yield of $25 \%$. The monosubstituted product SePDI-DPP was saved and used to synthesize the asymmetric SePDI-DPP-NPDI following the same DHA cross-coupling procedure. The asymmetric product was obtained in a $69 \%$ yield upon purification by column chromatography. Each compound was characterized by ${ }^{1} \mathrm{H}$ and ${ }^{13} \mathrm{C}$ NMR spectroscopy, MALDI mass spectrometry, and elemental analysis (see the supporting information for full synthetic details).

The aromatic regions of the ${ }^{1} \mathrm{H}$ NMR spectra of NPDI-DPP-NPDI, SePDI-DPP-NPDI, and SePDI-DPP-SePDI are shown Figure . Because of the differing effects of the heteroatom annulation on the electronic structure of the perylene core, the SePDI and NPDI display varying spectroscopic resonances. The ${ }^{1} \mathrm{H}$ NMR spectrum of SePDI-DPP-NPDI is almost an exact combination of the spectra of NPDI-DPP-NPDI and SePDI-DPP-SePDI, as shown in the overlapping spectra of Figure 2. This indicates that the SePDI and NPDI units of SePDI-DPPNPDI do not have any significant electronic influence on each other, despite full conjugation throughout the molecule. Prior DFT calculations on NPDI-DPP-NPDI indicated that there was a large dihedral angle between the DPP core and NPDI endcaps, indicating any electronic communication between the core and endcaps would be minimal. ${ }^{14}$ Therefore, any influence the 
NPDI and SePDI endcaps would have on each other in the asymmetric material would be near non-existent, which accounts for the consistency between the ${ }^{1} \mathrm{H}$ NMR spectra.
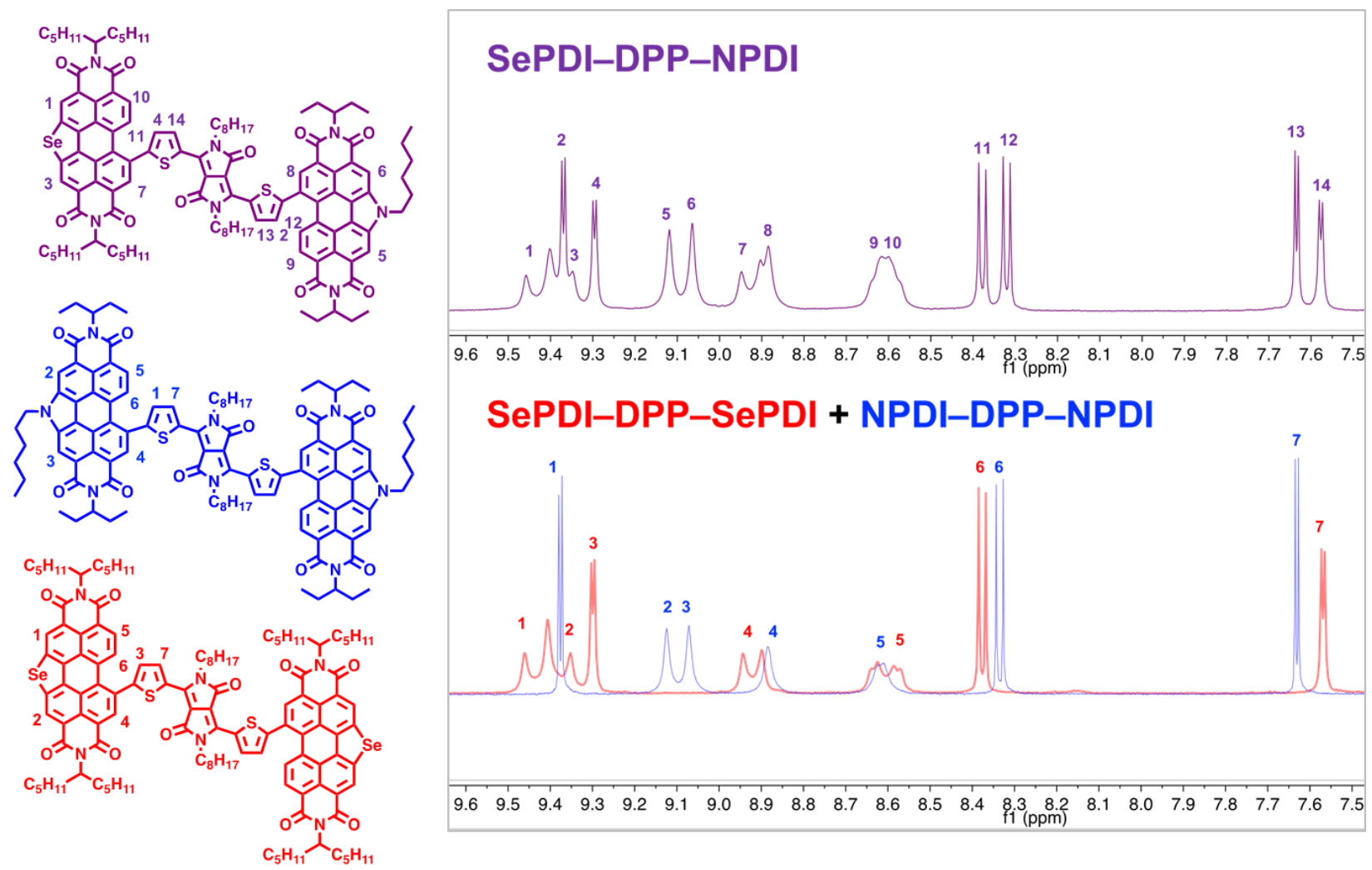

Figure 2. ${ }^{1} \mathrm{H}$ NMR spectra of the aromatic regions of SePDI-DPP-SePDI (red trace), NPDI-DPPNPDI (blue trace), and SePDI-DPP-NPDI (purple trace) with assignments shown.

\section{Thermal Properties}

The thermal properties of all three compounds were investigated by differential scanning calorimetry (DSC) and thermal gravimetric analysis (TGA). The DSC and TGA profiles of NPDIDPP-NPDI, SePDI-DPP-NPDI, and SePDI-DPP-SePDI are shown in Figure 3. Both NPDIDPP-NPDI and SePDI-DPP-SePDI and have no transitions from $100{ }^{\circ} \mathrm{C}$ to $375{ }^{\circ} \mathrm{C}$. The asymmetric SePDI-DPP-NPDI displays a distinct melt at $343{ }^{\circ} \mathrm{C}$, indicating that the asymmetry effects the solid-state organization of the material. NPDI-DPP-NPDI is the most thermally stable with a decomposition temperature of $428^{\circ} \mathrm{C}$, while SePDI-DPP-SePDI and SePDI-DPP-NPDI 
start to decompose at $391{ }^{\circ} \mathrm{C}$ and $395{ }^{\circ} \mathrm{C}$, respectively. This indicates that Se-annulation of PDI renders the material slightly less thermally stable than $\mathrm{N}$-annulation, which is to be expected given the disparity between $\mathrm{Se}-\mathrm{C}$ and $\mathrm{N}-\mathrm{C}$ bond strengths.
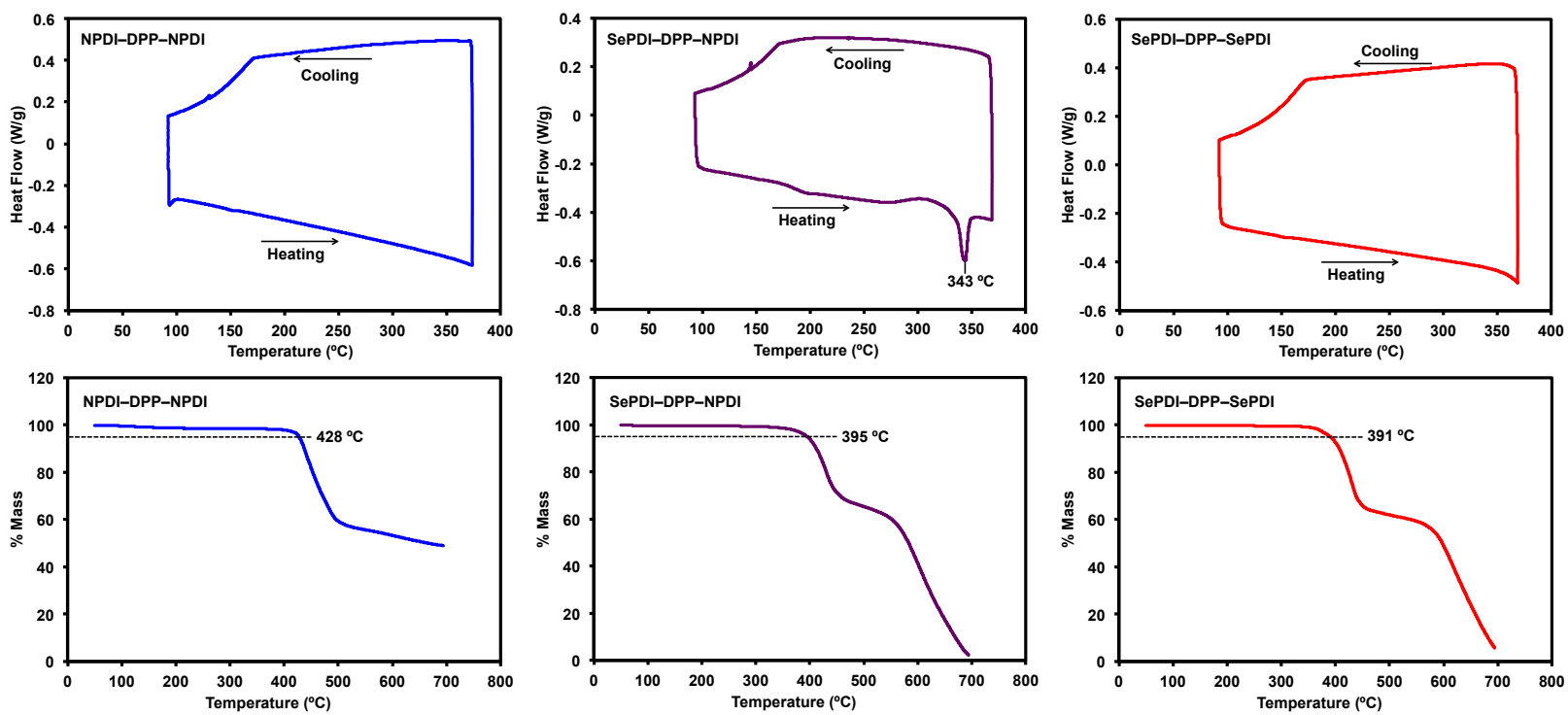

Figure 3. DSC (top) and TGA (bottom) profiles for NPDI-DPP-NPDI, SePDI-DPP-NPDI, and SePDI-DPP-SePDI.

\section{Electrochemical and Optical Properties}

The electrochemical properties were determined by cyclic and differential pulse voltammetry. Cyclic voltammograms are displayed in Figure 4. All compounds show fully reversible electrochemical reduction and oxidation behaviour. There are three reversible reduction waves for NPDI-DPP-NPDI (-1.2 V, -1.4 V, and -1.8 V), three for SePDI-DPP-SePDI (-1.1 V, $-1.3 \mathrm{~V}$ and $-1.8 \mathrm{~V})$ and five for SePDI-DPP-NPDI (-1.1 V, -1.2 V, -1.3 V, -1.5 V, and -1.8 V). In each species the DPP unit is reduced at $-1.8 \mathrm{~V}$ while reduction of the PDI units account for the other potentials, as shown in Figure 4 with the CVs for the individual components of each compound. $\mathrm{N}$ and Se annulation affect the electronic characteristics of the PDI unit differently which lead to slight shifts in the reduction potentials. Thus, reduction of NPDI $(-1.2 \mathrm{~V},-1.4 \mathrm{~V})$ occurs at higher potentials than reduction of SePDI $(-1.1 \mathrm{~V},-1.3 \mathrm{~V})$. As a result, the hybrid species 
in SePDI-DPP-NPDI displays four closely overlapped reductions waves, the exact $\mathrm{E}_{1 / 2}$ potentials for which were determined from the differential pulse voltammetry (SI, Figures S11). Each species oxidizes at $0.5 \mathrm{~V}$ and $0.8 \mathrm{~V}$ for oxidation of the DPP unit. There is an additional oxidation event for NPDI-DPP-NPDI at $1.3 \mathrm{~V}$ for the oxidation of the NPDI unit. This oxidation is not present in SePDI-DPP-NPDI despite the compound possessing an NPDI unit. SePDI does not reversibly oxidize in this range so SePDI-DPP-SePDI shows no other oxidation waves in its CV profile beyond the two for DPP oxidation.
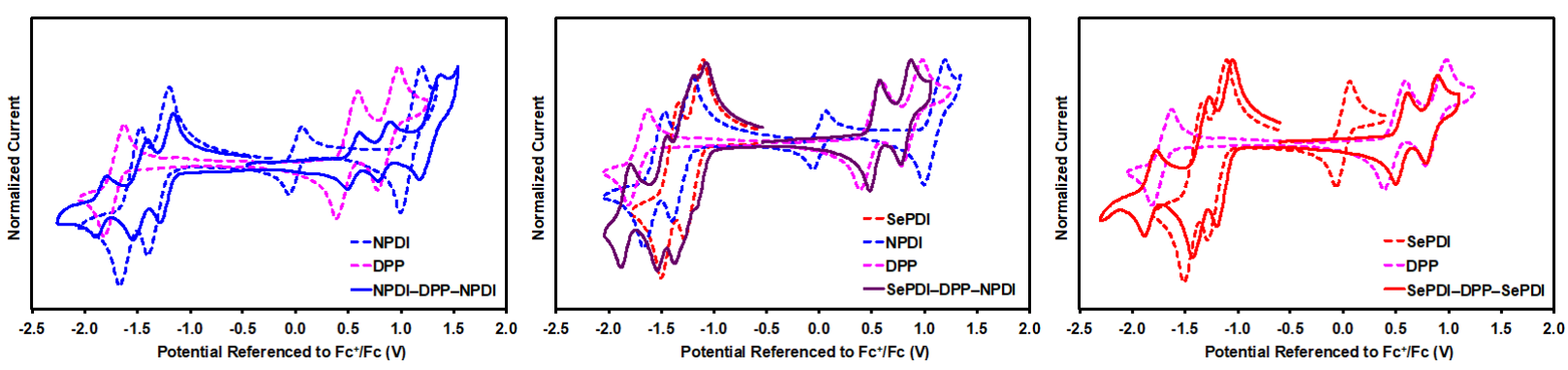

Figure 4. Cyclic voltammograms for NPDI-DPP-NPDI, ${ }^{13}$ SePDI-DPP-NPDI, and SePDI-DPPSePDI overlaid with their individual component cyclic voltammograms. CVs measured in $\mathrm{CH}_{2} \mathrm{Cl}_{2}$ at $100 \mathrm{mV} / \mathrm{s}$ with $\left[\mathrm{NBu}_{4}\right]\left[\mathrm{PF}_{6}\right]$ electrolyte, referenced to the ferrocene/ferrocenium redox couple.

The solution and solid-state UV/vis absorption spectra for each compound are displayed in Figure 5. The profiles for NPDI-DPP-NPDI and SePDI-DPP-SePDI displays the distinct 0-0 and 0-1 vibrionic bands for NPDI and SePDI electronic transitions at 532/509 $\mathrm{nm}$ and 509/476 nm, respectively. These NPDI and SePDI vibrionic transitions overlap in the profile for SePDI-DPPNPDI leading to maxima at 530,509, and $479 \mathrm{~nm}$. Thus, much like the CV profile, the absorption profile of SePDI-DPP-NPDI displays a combination of the individual components. This is more clearly displayed in Figure 6, which portrays the absorption profiles of SePDI and NPDI overlaid with the profiles of NPDI-DPP-NPDI, SePDI-DPP-NPDI, and SePDI-DPP-SePDI. Each profile also displays a low energy shoulder extending to $700 \mathrm{~nm}$ due to DPP absorption. ${ }^{13}$ The solid-state absorption profiles for each compound were measured with films spun-cast from $1.0 \mathrm{wt} / \mathrm{v} \%$ neat 
solutions in $\mathrm{CHCl}_{3}$ onto glass slides. As is common for solid-state absorption, the absorption profiles display a broadening and red shift of the $0-0$ and $0-1$ peaks, a decrease in the ratio between 0-0 and 0-1 peaks, and an increase in the prominence of the low energy shoulder. In the case of SePDI-DPP-NPDI, the peak broadening has the effect of removing the resolution between the SePDI and NPDI peaks and they appear as one very broad peak with $\lambda_{\max }$ ca. $515 \mathrm{~nm}$.
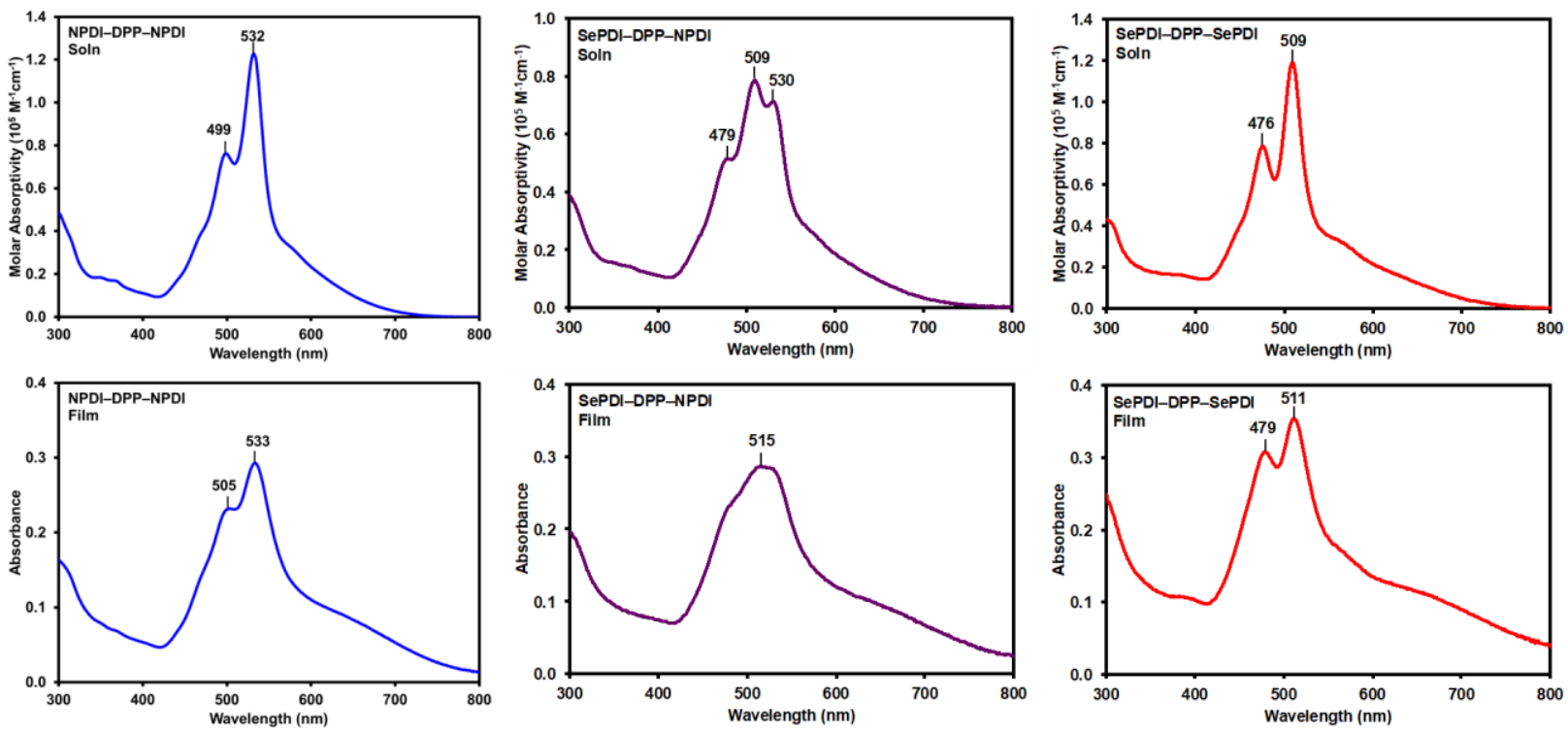

Figure 5. The solution (top) and solid-state (bottom) UV/vis absorption spectra for NPDI-DPPNPDI, ${ }^{13}$ SePDI-DPP-NPDI, and SePDI-DPP-SePDI. Solutions were measured in $\mathrm{CHCl}_{3}$ at 1.0 $\mathrm{wt} / \mathrm{v} \%$ concentration and thin films were spun-cast from $1.0 \mathrm{wt} / \mathrm{v} \% \mathrm{CHCl}_{3}$ stock solutions.

The molar absorptivity $(\varepsilon)$ of SePDI-DPP-SePDI was measured to be $121100 \mathrm{M}^{-1} \mathrm{~cm}^{-1}$ $\left(\lambda_{\max } 509 \mathrm{~nm}\right)$, comparable with the $121300 \mathrm{M}^{-1} \mathrm{~cm}^{-1}\left(\lambda_{\max } 532 \mathrm{~nm}\right) \varepsilon$ of NPDI-DPP-NPDI, ${ }^{13}$ while the $\varepsilon$ of SePDI-DPP-NPDI is lower at $80000 \mathrm{M}^{-1} \mathrm{~cm}^{-1}\left(\lambda_{\max } 509 \mathrm{~nm}\right)$. This is to be expected given that the absorption maximum for SePDI-DPP-NPDI only corresponds to absorption for one SePDI unit while the absorption maxima for SePDI-DPP-SePDI and NPDI-DPP-NPDI correspond to absorption for two SePDI units and two NPDI units, respectively. The integrated molar absorptivity for each species also shows a lower intensity for SePDI-DPP-NPDI with 
$124 \times 10^{5}, 107 \times 10^{5}$, and $129 \times 10^{5} \mathrm{M}^{-1} \mathrm{~cm}^{-1}$ for NPDI-DPP-NPDI, SePDI-DPP-NPDI, and SePDIDPP-SePDI, respectively. This indicates that the asymmetry in the material has resulted in a decrease in the visible light absorption of SePDI-DPP-NPDI compared to SePDI-DPP-SePDI and NPDI-DPP-NPDI. This is displayed in Figure 6 which overlays the absorption spectrum of SePDI-DPP-NPDI with the combined spectra of SePDI-DPP-SePDI and NPDI-DPP-NPDI. The profiles are identical in shape, but the profile of the asymmetric species is less intense than the combined profile of the two symmetric species. Photoluminescence (PL) spectra are shown in Figures S16 and S19 for SePDI-DPP-NPDI and SePDI-DPP-SePDI, respectively, both with small Stokes shifts. Complete optoelectronic data is tabulated in Table 1.
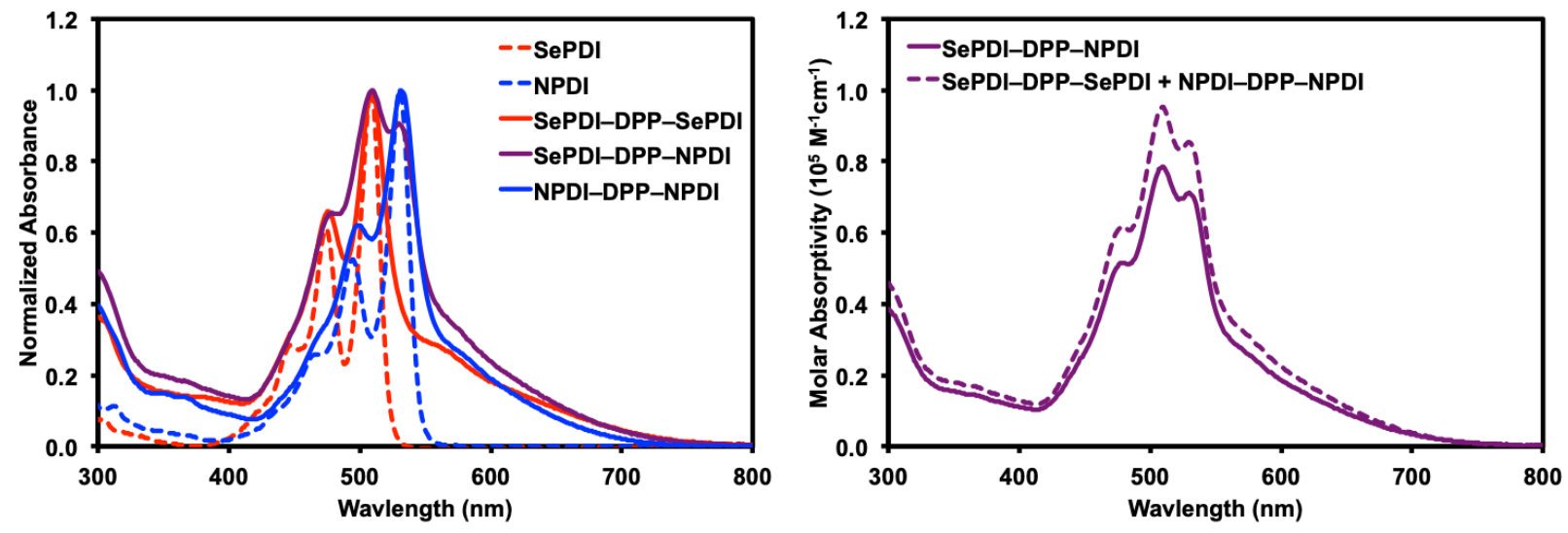

Figure 6. The normalized solution absorption spectra of SePDI, NPDI, SePDI-DPP-SePDI, SePDI-DPP-NPDI, and NPDI-DPP-NPDI (left) and the absorption spectra of SePDI-DPP-NPDI and combined average of SePDI-DPP-SePDI and NPDI-DPP-NPDI (right).

NPDI-DPP-NPDI has been shown to perform well as an NFA in OPVs. ${ }^{13,15}$ Given that SePDI-DPP-SePDI and SePDI-DPP-NPDI have shown similar optoelectronic properties to NPDI-DPP-NPDI, it is likely that they would serve as useful NFA materials. For example, the electron affinity (EA), calculated from the $\mathrm{E}_{1 / 2}$ of the first reduction wave, is higher for SePDIDPP-SePDI and SePDI-DPP-NPDI (3.7 eV for both) than for NPDI-DPP-NPDI (3.6 eV) due to the lower onset reduction potential for SePDI than NPDI. Combined with an IP of $5.3 \mathrm{eV}$ for each 
species, the electrochemical energy gaps are $1.6 \mathrm{eV}$ for SePDI-DPP-SePDI and SePDI-DPPNPDI, and $1.7 \mathrm{eV}$ for NPDI-DPP-NPDI (Table 1). These values are suitable for pairing with the plethora of donor polymers commercially available.

Table 1. Tabulated optoelectronic data for SePDI-DPP-SePDI, SePDI-DPP-NPDI, and NPDIDPP-NPDI. ${ }^{13}$

\begin{tabular}{|c|c|c|c|}
\hline (2) & NPDI-DPP-NPDI & SePDI-DPP-SePDI & SePDI-DPP-NPDI \\
\hline Ox EOnset $(V)$ & 0.48 & 0.48 & 0.48 \\
\hline $\mathrm{Ox} \mathrm{E}_{1 / 2}(\mathrm{~V})$ & $0.53,0.85,1.26$ & $0.54,0.83$ & $0.53,0.83$ \\
\hline Red E $E_{\text {Onset }}(\mathrm{V})$ & -1.14 & -1.06 & -1.04 \\
\hline $\operatorname{Red} \mathrm{E}_{1 / 2}(\mathrm{~V})$ & $-1.22,-1.47,-1.85$ & $-1.13,-1.36,-1.84$ & $\begin{array}{l}-1.12,-1.24,-1.32, \\
-1.49,-1.84\end{array}$ \\
\hline $\operatorname{IP}(e V)^{\mathrm{a}}$ & 5.3 & 5.3 & 5.3 \\
\hline $\mathrm{EA}(\mathrm{eV})^{\mathrm{b}}$ & 3.6 & 3.7 & 3.7 \\
\hline $\mathrm{E}_{\mathrm{g}}(\mathrm{eV})^{\mathrm{c}}$ & 1.7 & 1.6 & 1.6 \\
\hline Soln $\lambda_{\text {abs }}(\mathrm{nm})$ & 532,499 & 509,476 & $530,509,479$ \\
\hline Soln $\lambda_{\text {onset }}(\mathrm{nm})$ & 680 & 720 & 730 \\
\hline$\varepsilon\left(\mathrm{M}^{-1} \mathrm{~cm}^{-1}\right)$ & 121300 & 121100 & 80000 \\
\hline Film $\lambda_{\text {abs }}(\mathrm{nm})$ & 538,505 & 511,479 & 515 \\
\hline Film $\lambda_{\text {onset }}(\mathrm{nm})$ & 760 & 770 & 780 \\
\hline
\end{tabular}

\section{Density Functional Theory Calculations}


The compounds SePDI-DPP-NPDI and SePDI-DPP-SePDI were investigated by DFT calculations in order to compare experimental optoelectronic results with the theoretical results. Optimized geometries in the gas phase were calculated with alkyl chains substituted with methyl units using the B3LYP ${ }^{33-35}$ level of theory with $6-31 \mathrm{G}(\mathrm{d}, \mathrm{p})^{36-41}$ basis set. TD-SCF ${ }^{42}$ calculations were then performed on the optimized geometries to generate molecular orbital representations and simulated absorption spectra. The same DFT calculations were also performed for NPDIDPP-NPDI. ${ }^{43}$ Optimized geometries, molecular orbitals, and simulated absorption spectra for SePDI-DPP-NPDI and SePDI-DPP-SePDI are shown in Figure .

The optimized geometries of NPDI-DPP-NPDI, ${ }^{43}$ SePDI-DPP-NPDI, and SePDI-DPPSePDI are all similar with PDI-DPP dihedral angles in the range of $40^{\circ}-50^{\circ}$ and PDI-PDI dihedral angles in the range of $60^{\circ}-70^{\circ}$. In both SePDI-DPP-NPDI and SePDI-DPP-SePDI the HOMOs are localized on the DPP unit (energy levels of $-5.20 \mathrm{eV}$ and $-5.27 \mathrm{eV}$, respectively). In SePDIDPP-SePDI the LUMO $(-3.54 \mathrm{eV})$ and LUMO+1 $(-3.49 \mathrm{eV})$ are distributed across both SePDI units while in SePDI-DPP-NPDI the LUMO is localized to the SePDI unit and the LUMO+1 is localized on the NPDI unit. This agrees with the experimental electrochemical results that indicated reduction of SePDI occurs before reduction of NPDI in SePDI-DPP-NPDI (Figure 4). The HOMO and LUMO of NPDI-DPP-NPDI (-4.89 eV and $-3.26 \mathrm{eV}$, respectively) were also found to be localized on the DPP core and NPDI units, respectively. ${ }^{43}$

The simulated absorption spectrum of NPDI-DPP-NPDI was found to have a significant low energy transition $(900 \mathrm{~nm})$ associated with the HOMO to LUMO transition. The simulated absorption spectra of SePDI-DPP-SePDI also shows a low energy HOMO to LUMO transition at $870 \mathrm{~nm}$ while the simulated absorption spectra of SePDI-DPP-NPDI show low energy HOMO to LUMO and HOMO to LUMO+1 transitions at $872 \mathrm{~nm}$ and $778 \mathrm{~nm}$, respectively. This agrees with 
the experimental optical spectra of SePDI-DPP-NPDI and SePDI-DPP-SePDI (Figure 5) which show low energy shoulders around $580 \mathrm{~nm}$. Thus, the calculated data for SePDI-DPP-NPDI and SePDI-DPP-SePDI correlate well with experimental results and provide the same insights into their optoelectronic properties as the calculated data for NPDI-DPP-NPDI. 
A)

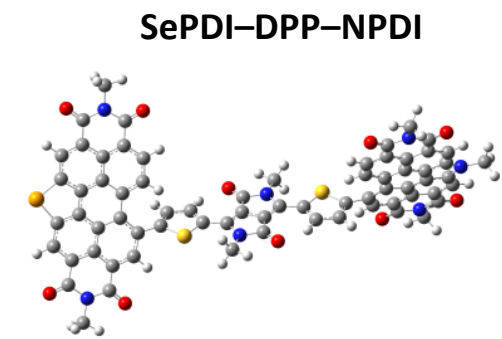

B)
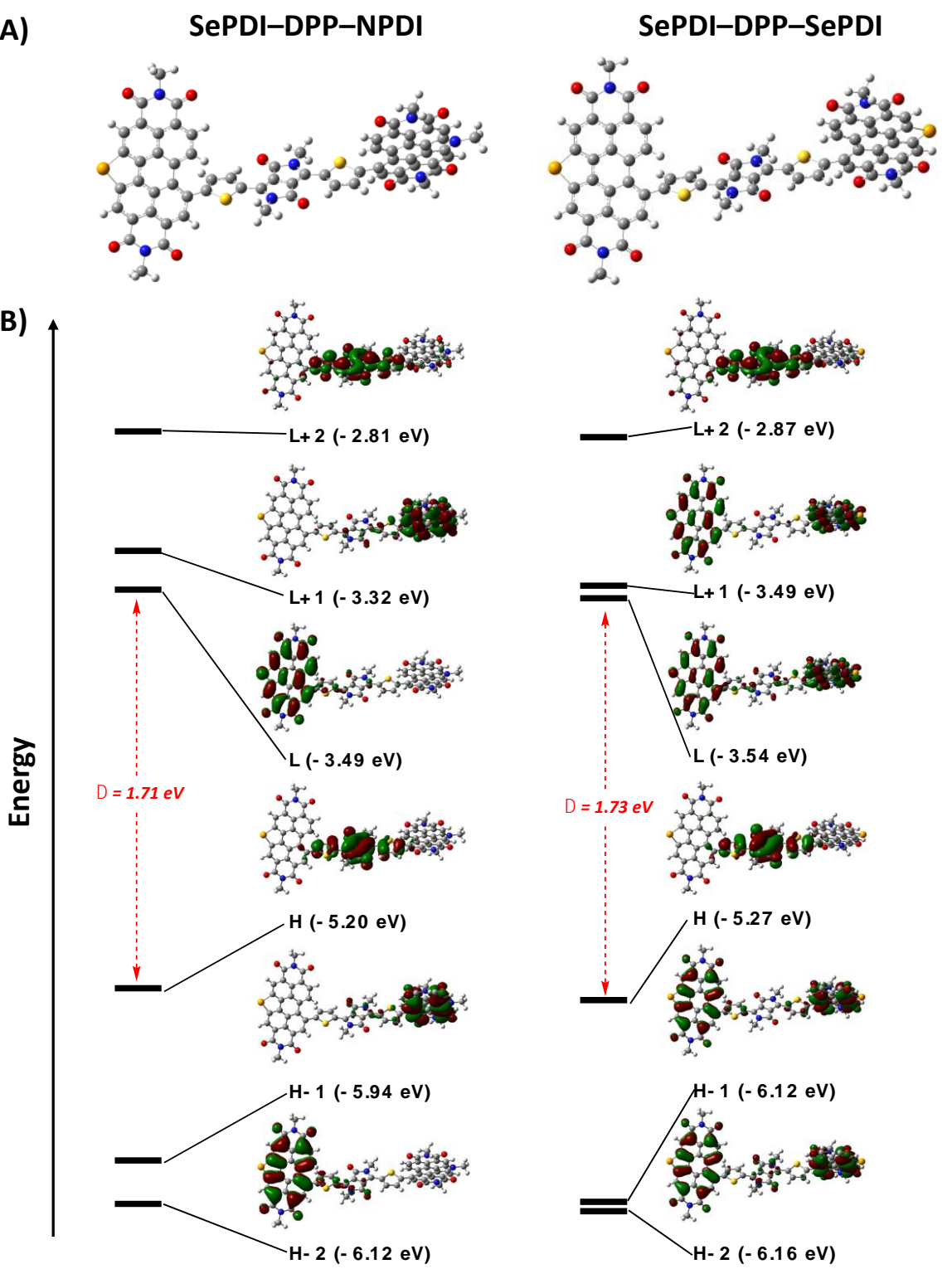

C)
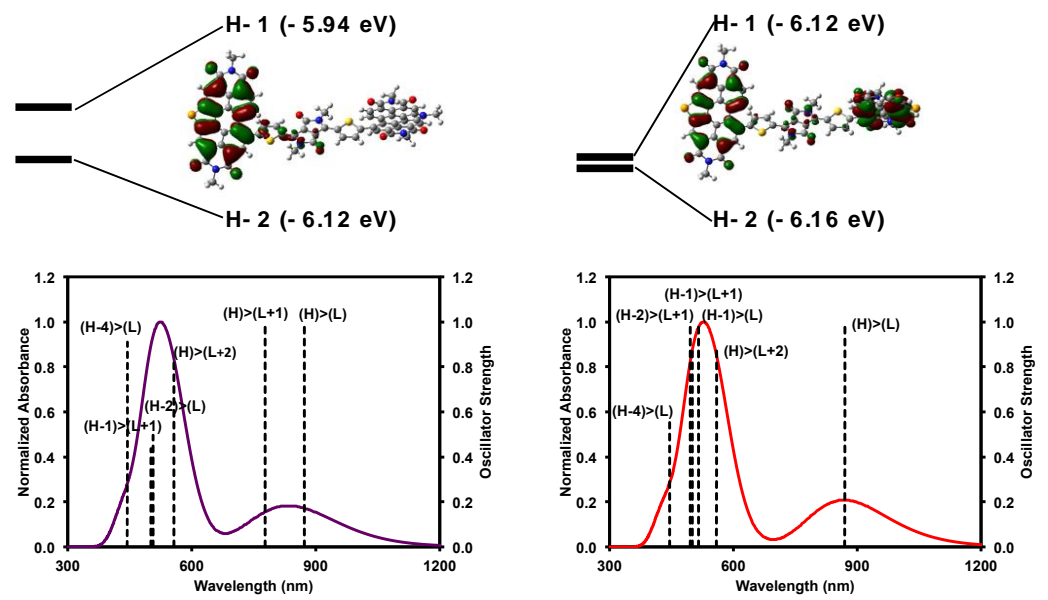

Figure 7. A) Optimized geometries, B) calculated electronic energy levels and energy gaps, and C) calculated optical absorption profile for SePDI-DPP-NPDI and SePDI-DPP-SePDI. Calculations were done on Gaussian $16^{44}$ input files and results were visualized using GaussView05. ${ }^{45}$ All alkyl chains were replaced with a methyl group. The B3LYP ${ }^{33-35}$ level of theory with 6-31G $(\mathrm{d}, \mathrm{p})^{36-41}$ basis set were used for the calculations. TD-SCF ${ }^{42}$ calculations were performed from the optimized geometry. The single point calculation was performed on these structures in order to generate molecular orbitals and simulated absorption spectra. 


\section{Solvent Vapour Annealing (SVA)}

Previous work with thin films of NPDI-DPP-NPDI showed that they respond to SVA treatment with $\mathrm{CHCl}_{3}$ and THF, reflected by stark changes in solid-state absorption profile. ${ }^{13,17}$ Given the similarities in the optical properties between NPDI-DPP-NPDI, SePDI-DPP-NPDI, and SePDI-DPP-SePDI, it is likely SVA treatment would also have similar effects on the thin films of SePDI-DPP-NPDI and SePDI-DPP-SePDI. For NPDI-DPP-NPDI, SVA treatment induces a change in the solid-state morphology that is reflected in the absorption profile. Specifically, there is a decrease in the prominence of the low energy shoulder at $680 \mathrm{~nm}$ and the emergence of a new higher energy peak at $586 \mathrm{~nm}$ as well as a red-shift, broadening, and decrease in intensity of the NPDI peaks (Figure). ${ }^{13}$ Such changes imply a reorganization primarily dictated by the DPP unit. In the case of $\mathrm{CHCl}_{3}$ vapours, these changes appeared after 2 minutes of annealing with optimum annealing time between 2 and 5 minutes. ${ }^{13,15}$ Blends of NPDI-DPP-NPDI with various donor polymers also displayed changes in the absorption profile after annealing with various solvents. ${ }^{17}$ These changes were accompanied by a large increase in OPV device performance. The largest increase in performance was seen in blends with the donor polymer PTB7-Th with THF SVA treatment for 5-10 minutes where PCE increased from $1.3 \%$ with no treatment to $5.7 \%$ with THF SVA. Thus, for this study, thin films of SePDI-DPP-NPDI and SePDI-DPP-SePDI neat and blended with PTB7-Th were subjected to SVA treatment with THF for up to 10 minutes.

Thin films of SePDI-DPP-NPDI and SePDI-DPP-SePDI and were spun-cast at $1500 \mathrm{rpm}$ for 60 seconds onto glass slides from $1.0 \mathrm{wt} / \mathrm{v} \% \mathrm{CHCl}_{3}$ solutions. Films were exposed to THF vapours for $1,3,5$, and 10 minutes. After 5 minutes of SVA a decrease in intensity in the low energy shoulder, emergence of a new peak at $580 \mathrm{~nm}$, peak broadening, and red-shift in the 
absorption maxima was observed (Figure 8). Annealing for longer than 5 minutes did not result in any further changes in the film spectra (SI, Figure S20).
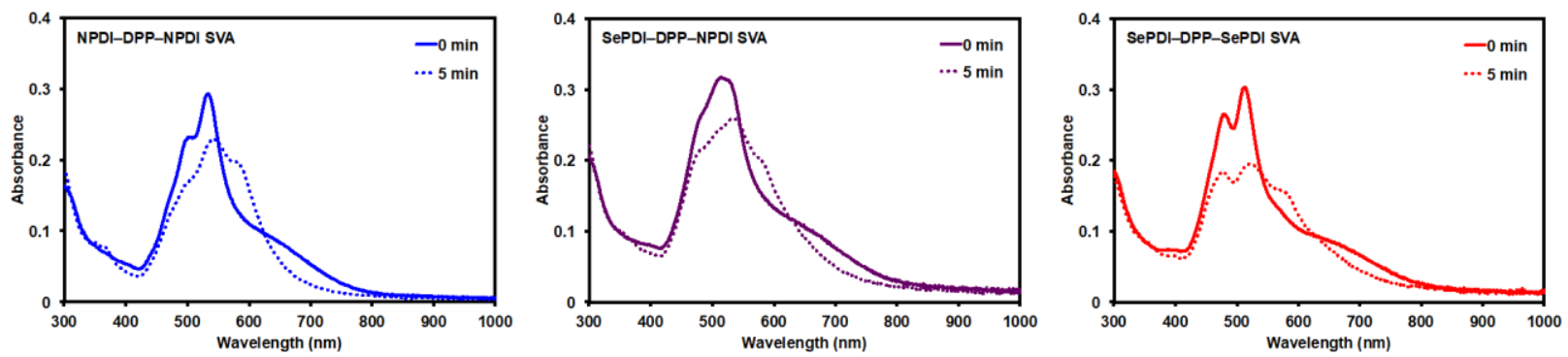

Figure 8. Thin film absorption spectra of NPDI-DPP-NPDI, ${ }^{13}$ SePDI-DPP-NPDI, and SePDIDPP-SePDI spun-cast from $1.0 \mathrm{wt} / \mathrm{v} \% \mathrm{CHCl}_{3}$ solutions and treated with a THF SVA step for 5 minutes.

Blends of PTB7-Th with SePDI-DPP-NPDI and SePDI-DPP-SePDI were prepared in $\mathrm{CHCl}_{3}$ at $1.0 \mathrm{wt} / \mathrm{v} \%$ concentration with 50:50 and 30:70 D/A weight ratios. Thin films were spuncast at $1500 \mathrm{rpm}$ for 60 seconds onto glass slides and exposed to THF vapours for 5 minutes. The UV/Vis absorption profiles for as cast and 5-minute annealed films are displayed in Figure 9. Each blend profile displays broad absorption over the entire visible spectrum due to the complementary absorption between donor and acceptor. For both SePDI-DPP-NPDI blends, SVA for 5 min led to the emergence of a new band at $580 \mathrm{~nm}$. The blend ratio has not had an effect on the response to SVA treatment, as was the case for blends of PTB7-Th/NPDI-DPP-NPDI. ${ }^{13}$ However, it should be noted that the emergence of the peak at $580 \mathrm{~nm}$ in the PTB7-Th/SePDI-DPP-NPDI blends only appeared after 5 minutes of SVA while in PTB7-Th/NPDI-DPP-NPDI films this peak appeared after 2 minutes, indicating that SePDI substitution has had some influence on solid state morphology. Substituting both NPDI units for SePDI units has had a much more significant influence on morphology. For the PTB7-Th/SePDI-DPP-SePDI 50:50 blend film SVA treatment has had no effect on the absorption profile while for the 30:70 blend film SVA treatment has 
induced the emergence of a peak at $580 \mathrm{~nm}$. These results indicate that substituting both NPDI units for SePDI has significantly affected the solid-state morphology making blends of PTB7-Th and SePDI-DPP-SePDI much more sensitive to D/A ratio in a way that blends of PTB7-Th and NPDI-DPP-NPDI are not. While substituting just one NPDI for SePDI does not lead to the same sensitivity to D/A ratio in blends of PTB7-Th and SePDI-DPP-NPDI, it has made these films respond more slowly than PTB7-Th/NPDI-DPP-NPDI films.
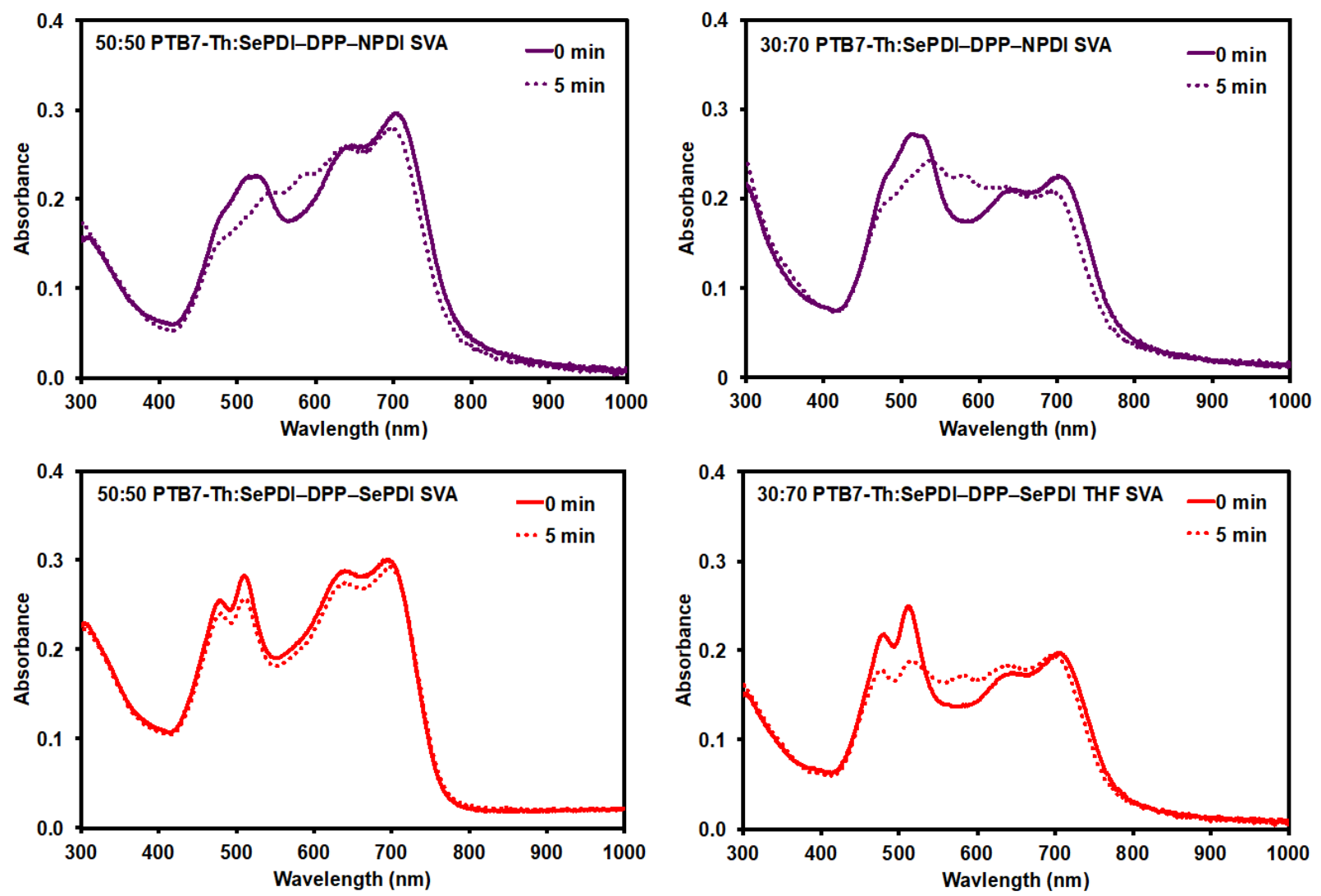

Figure 9. Thin film absorption profiles of PTB7-Th with SePDI-DPP-NPDI and SePDI-DPPSePDI in 50:50 and 30:70 D/A weight ratios spun-cast from $1.0 \mathrm{wt} / \mathrm{v} \% \mathrm{CHCl}_{3}$ solutions and treated with THF SVA. 


\section{Organic Photovoltaics}

Following our previously established protocols, ${ }^{13,16-18,25}$ proof-of-concept OPV devices were fabricated to further characterize and compare the two new compounds SePDI-DPP-NPDI and SePDI-DPP-SePDI. The inverted structure of ITO/ZnO/PTB7-Th:acceptor/MoO $/ \mathrm{Ag}$ structure where acceptor $=$ SePDI-DPP-NPDI or SePDI-DPP-SePDI was used for all devices. Bulk heterojunction active layers were spun-cast from $\mathrm{CHCl}_{3}$ solutions (10 $\mathrm{mg} / \mathrm{mL}$ total solids) in air at room temperature and measured with and without a 5 minute SVA treatment using THF vapour. A 3:7 donor to acceptor ratio was used considering all blends showed changes in the optical absorption profile at this ratio (vide supra) and having a higher acceptor loading has previously led to best results. ${ }^{13,17,46}$

OPV devices based on PTB7-Th:SePDI-DPP-NPDI and PTB7-Th:SePDI-DPP-SePDI active layers without SVA treatment gave best power conversion efficiency (PCE) values of $0.5 \%$ and $1.3 \%$, respectively (Figure 10, Table 2). The low PCE is consistent with previously reported devices based on PTB7-Th:NPDI-DPP-NPDI active layers where a disorganized, amorphous nanomorphology persisted. ${ }^{17}$ Upon SVA treatment of the active layers with THF vapour the PCE increased to $0.7 \%$ and $1.8 \%$ for PTB7-Th:SePDI-DPP-NPDI and PTB7-Th:SePDI-DPP-SePDI active layers, respectively (Figure 10, Table 2). The increase in PCE is primarily a result of increased short-circuit current $\left(\mathrm{J}_{\mathrm{sc}}\right)$ and is reflected in the external quantum efficiency spectra. Analysis of the optical absorption spectra of the devices shows the expected increase in optical density from 550-600 $\mathrm{nm}$ indicating the acceptor molecules are rearranging in the devices. Unfortunately, while both types of devices show an improved PCE upon SVA, the change is far less than that observed for devices based on the NPDI-DPP-NPDI acceptor. ${ }^{17}$ It is worth pointing out that best PTB7-Th:NPDI-DPP-NPDI based devices gave open circuit voltages (Voc) of 0.98 
V. For the best PTB7-Th:SePDI-DPP-SePDI based devices the $\mathrm{V}_{\mathrm{OC}}$ is reduced to $0.87 \mathrm{~V}$ which is consistent with the increased electron affinity of the acceptor due to Se for $\mathrm{N}$ substitution. The best PTB7-Th:SePDI-DPP-NPDI based devices had much lower Voc values of $0.76 \mathrm{~V}$, which was not expected considering the electron affinity (i.e. first reduction potential) of SePDI-DPPNPDI (ca. -1.12 V) was similar to SePDI-DPP-SePDI (ca. -1.13 V). This implies that a unique solid-state organization of the asymmetric molecule is leading to different electronic behaviour, a phenomenon that needs to be explored further. The changes in surface roughness of the active layer films were probed before and after SVA treatment. Before the active layers were smooth with minimal features. Upon SVA treatment the films roughen with larger domains forming what appear to be a more ordered morphology (Figure S21 and S22). A more organized bulkheterojunction can improve charge extraction and can help explain the increase in $\mathbf{J}_{\mathrm{SC}}$. This is consistent with our previous findings. ${ }^{17}$
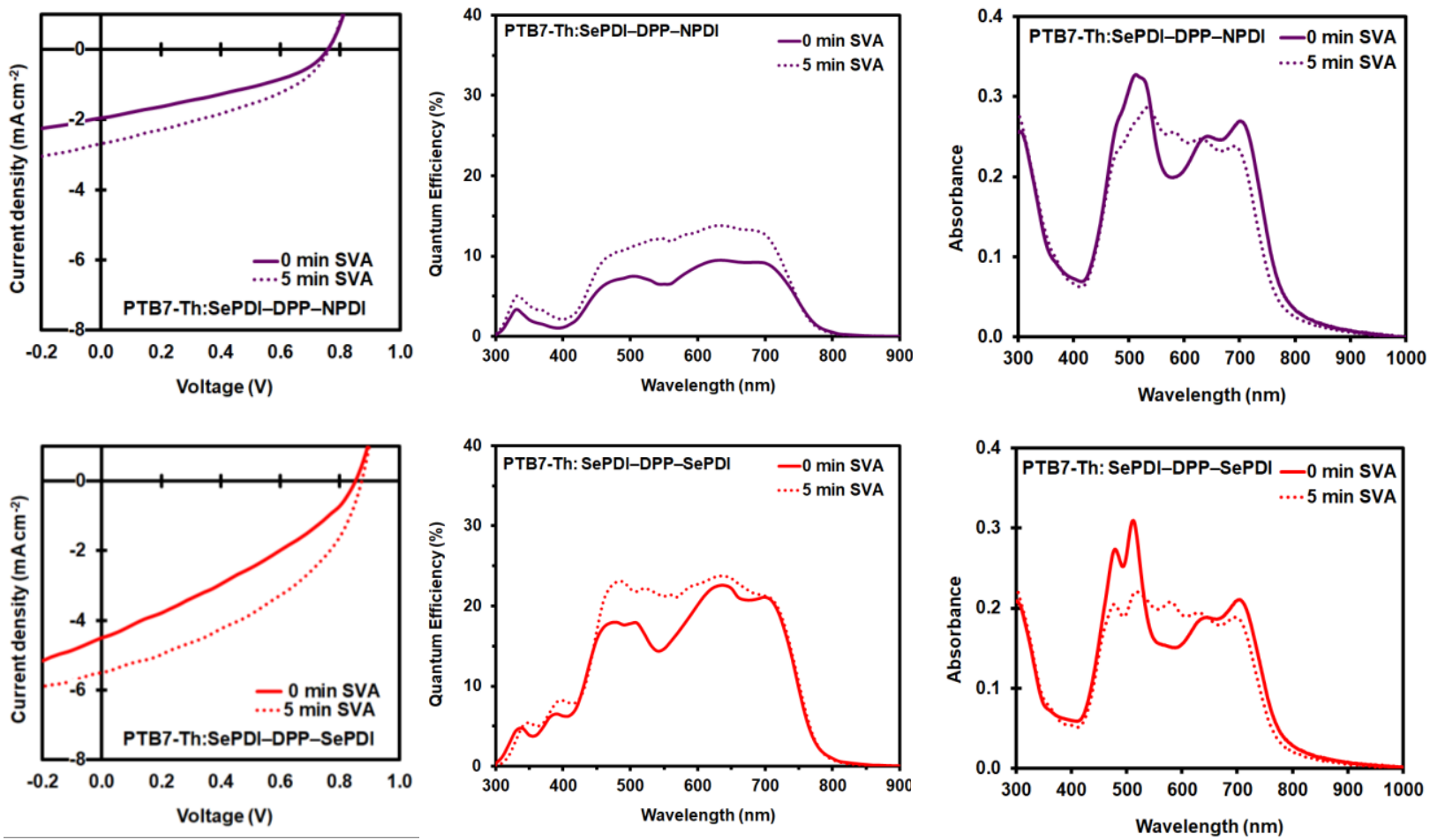

Figure 10. Current-voltage curves (left), external quantum efficiency spectra (middle), and optical absorption spectra (right) of organic photovoltaic devices with an ITO/ZnO/PTB7- 
Th:acceptor/ $\mathrm{MoO}_{\mathrm{x}} / \mathrm{Ag}$ structure where acceptor = SePDI-DPP-NPDI (top, purple) or SePDIDPP-SePDI (bottom, red). PTB7-Th:acceptor ratio $=3: 7$. For SVA treated devices the active layer was exposed to THF vapour for 5 minutes in a closed chamber prior to top contact deposition.

Table 2. Tabulated organic photovoltaic device data

\begin{tabular}{|c|c|c|c|c|}
\hline Photoactive layer & $\mathrm{V}_{\mathrm{OC}}(\mathrm{V})$ & $\mathrm{J}_{\mathrm{sc}}\left(\mathrm{mA} / \mathrm{cm}^{2}\right)$ & Fill Factor (\%) & Efficiency $(\%)$ \\
\hline \multicolumn{5}{|c|}{ PTB7-Th:SePDI-DPP-NPDI } \\
\hline $0 \min \mathrm{SVA}$ & $0.74(0.76)$ & $1.8(2.0)$ & $35(37)$ & $0.5(0.5)$ \\
\hline 5 min SVA & $0.74(0.76)$ & $2.6(2.7)$ & $37(38)$ & $0.7(0.8)$ \\
\hline \multicolumn{5}{|c|}{ PTB7-Th:SePDI-DPP-SePDI } \\
\hline $0 \min \mathrm{SVA}$ & $0.84(0.85)$ & $3.8(4.5)$ & $33(33)$ & $1.0(1.3)$ \\
\hline $5 \min \mathrm{SVA}$ & $0.85(0.87)$ & $5.3(5.5)$ & $39(41)$ & $1.8(2.0)$ \\
\hline
\end{tabular}

${ }^{a}$ Average of min. eight devices with metrics of champion devices in parentheses.

${ }^{\mathrm{b}}$ Photoactive layers processed from chloroform $(10 \mathrm{mg} / \mathrm{mL}$ total solids concentration) using a 3:7 donor:acceptor blend ratio without and with THF SVA.

\section{Conclusion}

In this contribution we have presented two new organic $\pi$-conjugated materials, namely SePDI-DPP-NPDI and SePDI-DPP-SePDI, which are the selenium annulated PDI derivatives of our teams known NPDI-DPP-NPDI non-fullerene acceptor. ${ }^{13}$ The molecules were synthesized using direct (hetero)arylation cross-coupling methods and it was found that the SePDI building block was a poorer coupling partner than the NPDI building block with the DPP chromophore. In comparing the materials properties, the main finding was the SePDI building block has the primary effect of increasing the electron affinity of the molecules while decreasing the propensity for molecular rearrangement in the thin film upon solvent vapour annealing, a known technique to induce crystallization in organic films. As a result, organic photovoltaic devices based on the SePDI compounds with the donor PTB7-Th showed lower open-circuit voltages and lower overall performance than the all NPDI analogue. To not discount these new non-fullerene acceptors, the 
pairing with PTB7-Th is clearly not ideal and a systematic evaluation of donor polymers and film processing conditions is warranted. As a final comment this work serves to contradict the literature where non-fullerene acceptors based on the selenium annulated PDI seems to outperform those based on the nitrogen annulated PDI and that careful choice of molecular architecture is required to maximize organic photovoltaic performance.

\section{Acknowledgments}

GCW acknowledges the Canada Research Chairs Program, CFI JELF (34102), NSERC DG (201904392), and the University of Calgary. TAW and MN thank the University of Calgary for additional financial support.

\section{References}

1S. R. Forrest, Nature, 2004, 428, 911-918.

2 Y. Sun, G. C. Welch, W. L. Leong, C. J. Takacs, G. C. Bazan and A. J. Heeger, Nat. Mater., 2012, 11, 44-48.

3Q. Zhang, B. Kan, F. Liu, G. Long, X. Wan, X. Chen, Y. Zuo, W. Ni, H. Zhang, M. Li, Z. Hu, F. Huang, Y. Cao, Z. Liang, M. Zhang, T. P. Russell and Y. Chen, Nat. Photonics, 2015, 9, 3541.

4J. Liu, S. Chen, D. Qian, B. Gautam, G. Yang, J. Zhao, J. Bergqvist, F. Zhang, W. Ma, H. Ade, O. Inganäs, K. Gundogdu, F. Gao and H. Yan, Nat. Energy, 2016, 1, 16089.

5J. Hou, O. Inganäs, R. H. Friend and F. Gao, Nat. Mater., 2018, 17, 119-128.

6A. Facchetti, Chem. Mater., 2011, 23, 733-758.

7J. Mei, Y. Diao, A. L. Appleton, L. Fang and Z. Bao, J. Am. Chem. Soc., 2013, 135, 6724-6746. 8H. Sirringhaus, Adv. Mater., 2014, 26, 1319-1335.

9M. C. Gather, A. Köhnen and K. Meerholz, Adv. Mater., 2011, 23, 233-248.

10 L. Xiao, Z. Chen, B. Qu, J. Luo, S. Kong, Q. Gong and J. Kido, Adv. Mater., 2011, 23, 926-952.

11 R.-P. Xu, Y.-Q. Li and J.-X. Tang, J. Mater. Chem. C, 2016, 4, 9116-9142.

12 A. D. Hendsbee, J.-P. Sun, W. K. Law, H. Yan, I. G. Hill, D. M. Spasyuk and G. C. Welch, Chem. Mater., 2016, 28, 7098-7109.

13 S. M. McAfee, S. V. Dayneko, P. Josse, P. Blanchard, C. Cabanetos and G. C. Welch, Chem. Mater., 2017, 29, 1309-1314.

14 S. M. McAfee, S. V. Dayneko, A. D. Hendsbee, P. Josse, P. Blanchard, C. Cabanetos and G. C. Welch, J. Mater. Chem. A, 2017, 5, 11623-11633.

15 D. Zomerman, J. Kong, S. M. McAfee, G. C. Welch and T. L. Kelly, ACS Appl. Energy Mater., 2018, 1, 5663-5674.

16 S. M. McAfee, A.-J. Payne, S. V. Dayneko, G. P. Kini, C. E. Song, J.-C. Lee and G. C. Welch, J. Mater. Chem. A, 2017, 5, 16907-16913. 
17 S. M. McAfee, A.-J. Payne, A. D. Hendsbee, S. Xu, Y. Zou and G. C. Welch, Sol. RRL, 2018, 2, 1800143.

18 S. M. McAfee and G. C. Welch, The Chemical Record, 2019, 19, 989-1007.

19 H. Langhals and S. Kirner, European Journal of Organic Chemistry, 2000, 2000, 365-380.

20 S. V. Dayneko, A. D. Hendsbee and G. C. Welch, Chem. Commun., 2017, 53, 1164-1167.

21 F. You, X. Zhou, H. Huang, Y. Liu, S. Liu, J. Shao, B. Zhao, T. Qin and W. Huang, New J. Chem., 2018, 42, 15079-15087.

22 T. A. Welsh, A. Laventure and G. C. Welch, Molecules, 2018, 23, 931.

23 T. A. Welsh, A. Laventure, T. Baumgartner and G. C. Welch, J. Mater. Chem. C, 2018, 6, 2148-2154.

24 A.-J. Payne, S. Li, S. V. Dayneko, C. Risko and G. C. Welch, Chem. Commun., 2017, 53, 10168-10171.

25 A.-J. Payne, N. A. Rice, S. M. McAfee, S. Li, P. Josse, C. Cabanetos, C. Risko, B. H. Lessard and G. C. Welch, ACS Appl. Energy Mater., 2018, 1, 4906-4916.

26 A.-J. Payne, J. Song, Y. Sun and G. C. Welch, Chem. Commun., 2018, 54, 11443-11446.

27 T. A. Welsh, A.-J. Payne and G. C. Welch, New J. Chem., 2019, 43, 9333-9337.

28 D. Sun, D. Meng, Y. Cai, B. Fan, Y. Li, W. Jiang, L. Huo, Y. Sun and Z. Wang, J. Am. Chem. Soc., 2015, 137, 11156-11162.

29 D. Meng, D. Sun, C. Zhong, T. Liu, B. Fan, L. Huo, Y. Li, W. Jiang, H. Choi, T. Kim, J. Y. Kim, Y. Sun, Z. Wang and A. J. Heeger, J. Am. Chem. Soc., 2016, 138, 375-380.

30 Y. Duan, X. Xu, Y. Li, Z. Li and Q. Peng, Macromol. Rapid Commun., 2017, 38, 1700405.

31 D. Meng, H. Fu, C. Xiao, X. Meng, T. Winands, W. Ma, W. Wei, B. Fan, L. Huo, N. L. Doltsinis, Y. Li, Y. Sun and Z. Wang, J. Am. Chem. Soc., 2016, 138, 10184-10190.

32 Z. Luo, T. Liu, Z. Chen, Y. Xiao, G. Zhang, L. Huo, C. Zhong, X. Lu, H. Yan, Y. Sun and C. Yang, Adv. Sci., 2019, 6, 1802065.

33 A. D. Becke, Phys. Rev. A, 1988, 38, 3098-3100.

34 C. Lee, W. Yang and R. G. Parr, Phys. Rev. B, 1988, 37, 785-789.

35 B. Miehlich, A. Savin, H. Stoll and H. Preuss, Chemical Physics Letters, 1989, 157, 200206.

36 W. J. Hehre, R. Ditchfield and J. A. Pople, The Journal of Chemical Physics, 1972, 56, 2257-2261.

37 P. C. Hariharan and J. A. Pople, Theoret. Chim. Acta, 1973, 28, 213-222.

38 M. M. Francl, W. J. Pietro, W. J. Hehre, J. S. Binkley, M. S. Gordon, D. J. DeFrees and J. A. Pople, The Journal of Chemical Physics, 1982, 77, 3654-3665.

39 R. C. Binning and L. A. Curtiss, J. Comput. Chem., 1990, 11, 1206-1216.

40 V. A. Rassolov, J. A. Pople, M. A. Ratner and T. L. Windus, The Journal of Chemical Physics, 1998, 109, 1223-1229.

41 V. A. Rassolov, M. A. Ratner, J. A. Pople, P. C. Redfern and L. A. Curtiss, J. Comput. Chem., 2001, 22, 976-984.

42 R. Bauernschmitt and R. Ahlrichs, Chemical Physics Letters, 1996, 256, 454-464.

43 S. M. McAfee, S. V. Dayneko, A. D. Hendsbee, P. Josse, P. Blanchard, C. Cabanetos and G. C. Welch, J. Mater. Chem. A, 2017, 5, 11623-11633.

44 M. Frisch, G. Trucks, H. Schlegel, G. Scuseria, M. Robb, J. Cheeseman, G. Scalmani, V. Barone, B. Mennucci, G. Petersson, H. Nakatsuji, M. Caricato, X. Li, H. Hratchian, A. Izmaylov, J. Bloino, G. Zheng, J. Sonnenberg, M. Hada, M. Ehara, K. Toyota, R. Fukuda, J. Hasegawa, M. Ishida, T. Nakajima, Y. Honda, O. Kitao, H. Nakai, T. Vreven, J. Montgomery, J. Peralta, F. 
Ogliaro, M. Bearpark, J. Heyd, E. Brothers, K. Kudin, V. Staroverov, R. Kobayashi, J. Normand, K. Raghavachari, A. Rendell, J. Burant, S. Iyengar, J. Tomasi, M. Cossi, N. Rega, J. Millam, M. Klene, J. Knox, J. Cross, V. Bakken, C. Adamo, J. Jaramillo, R. Gomperts, R. Stratmann, O. Yazyev, A. Austin, R. Cammi, C. Pomelli, J. Ochterski, R. Martin, K. Morokuma, V. Zakrzewski, G. Voth, P. Salvador, J. Dannenberg, S. Dapprich, A. Daniels, Farkas, J. Foresman, J. Ortiz, J. Cioslowski and D. Fox, Gaussian 16, Revision A.03, Gaussian, Inc., Wallingford CT. 45 R. Dennington, T. A. Keith and J. M. Millam, Semichem Inc., Shawnee Mission KS.

46 S. V. Dayneko, A. D. Hendsbee and G. C. Welch, Small Methods, 2018, 2, 1800081.

TOC

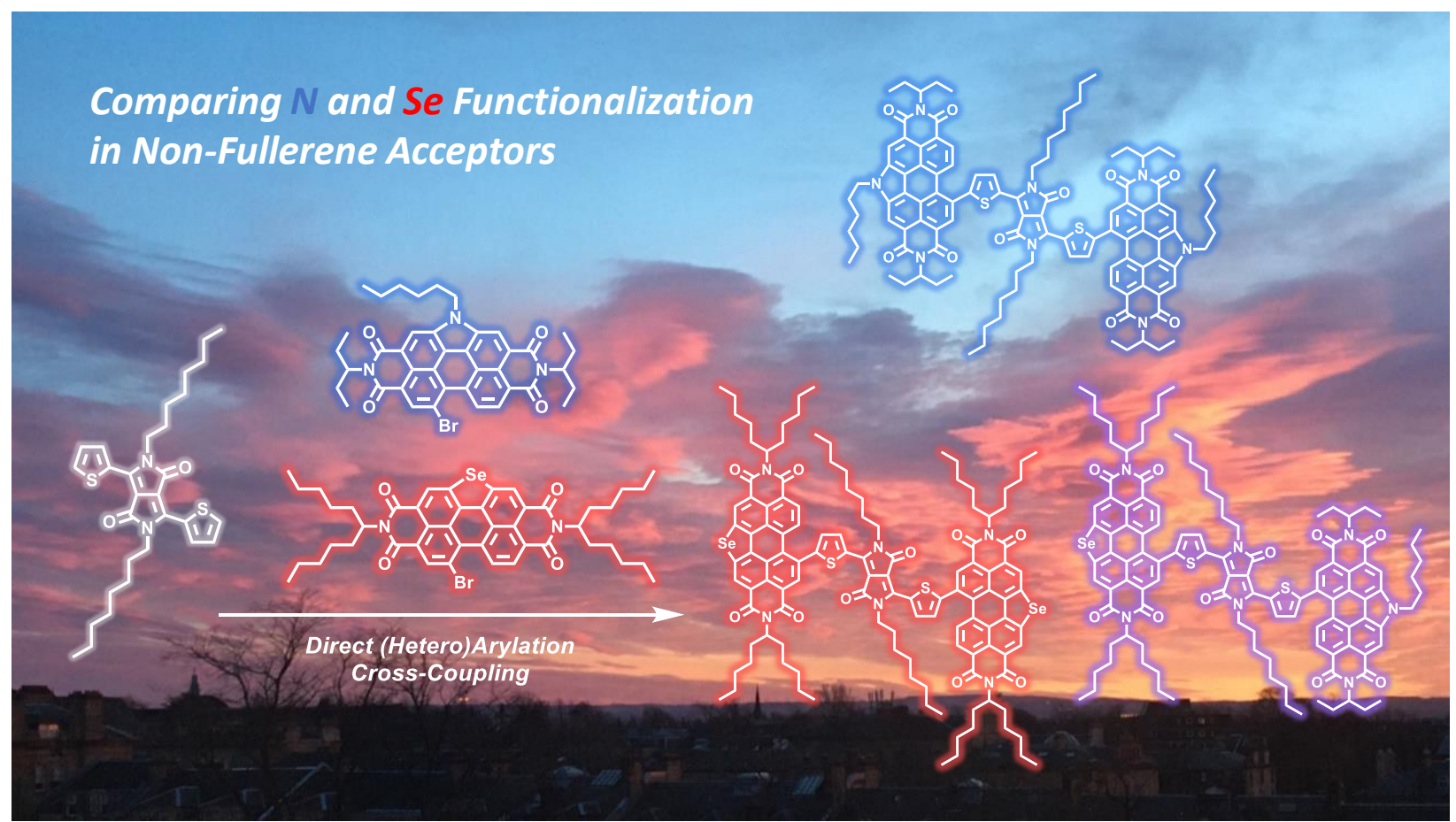




\title{
SUPPORTING INFORMATION
}

\section{Diketopyrrolopyrrole Derivatives Functionalized with N-Annulated PDI and Se-Annulated PDI by Direct (Hetero)Arylation Methods}

\author{
Thomas A. Welsh, Maryam Nazari, and Gregory C. Welch* \\ Department of Chemistry, University of Calgary \\ 2500 University Drive NW Calgary, AB, Canada T2N 1N4. \\ *Corresponding Authors \\ Email: gregory.welch@ucalgary.ca \\ Phone Number: 1-403-210-7603
}


$\underline{\text { Table of Contents }}$

Materials and Methods $\quad$ S-3

Experimental $\quad$ S-4

Solution NMR Spectra $\quad$ S-6

Mass Spectrometry (MALDI-TOF) S-9

Elemental Analysis $\quad$ S-10

Optoelectronic Characterization (Cyclic voltammetry/UV-Vis) S-11

Density Functional Theory Calculations $\quad$ S-17

Organic Photovoltaics $\quad$ S-18

References $\quad$ S-19 


\section{Materials and Methods}

Materials: SiliaCat ${ }^{\circledR}$ DPP-Pd was received from SiliCycle. All remaining reagents were purchased from Sigma-Aldrich. Dimethyl acetamide solvent was dried by filtering through $\mathrm{MgSO}_{4}$, stored over $3 \AA$ molecular sieves, and purged with $\mathrm{N}_{2}$ bubbling before use. All other solvents and materials purchased were used without further purification.

Nuclear Magnetic Resonance (NMR): ${ }^{1} \mathrm{H}$ and ${ }^{13} \mathrm{C}$ spectra were recorded on a Bruker Avance$500 \mathrm{MHz}$ spectrometer at $300 \mathrm{~K}$. Chemical shifts are reported in parts per million (ppm). Multiplicities are reported as: singlet (s), doublet (d), doublet of doublets (dd), triplet (t), multiplet (m), quartet (q), and broad (br).

High-resolution Mass Spectrometry (HRMS): High-resolution MALDI mass spectrometry measurements were performed courtesy of Jian Jun (Johnson) Li in the Chemical Instrumentation Facility at the University of Calgary. A Bruker Autoflex III Smartbeam MALDI-TOF (Na:YAG laser, $355 \mathrm{~nm}$ ), setting in positive or negative reflective mode, was used to acquire spectra. Operation settings were all typical, e.g. laser offset 62-69; laser frequency $200 \mathrm{~Hz}$; and number of shots 300. The target used was Bruker MTP 384 ground steel plate target. Sample solution $(\sim 1$ $\mu \mathrm{g} / \mathrm{mL}$ in dichloromethane) was mixed with matrix trans-2-[3-(4-tert-Butylphenyl)-2-methyl-2propenylidene]malononitrile (DCTB) solution $(\sim 5 \mathrm{mg} / \mathrm{mL}$ in methanol). Pipetted $1 \mu \mathrm{l}$ solution above to target spot and dried in the fume hood.

CHN Analysis: Elemental analysis was performed by Jian Jun Li in the Chemical Instrumentation Facility at the University of Calgary. A Perkin Elmer 2400 Series II CHN Elemental Analyzer was used to obtain CHN data from a minimum of $3 \mathrm{mg}$ of sample with particle sizes ranging between 0.2 and $0.5 \mathrm{~mm}$ in diameter. Results were obtained in duplicate.

Cyclic Voltammetry (CV): Electrochemical measurements were performed using a Model 1200B Series Handheld Potentiostat by $\mathrm{CH}$ Instruments Inc. The cyclic voltammetry experiments were performed in anhydrous solution with $\sim 0.1 \mathrm{M}$ tetrabutylammonium hexafluorophosphate $\left(\mathrm{TBAPF}_{6}\right)$ as the supporting electrolyte using either dichloromethane solvent with Ag wire pseudo reference, Pt wire counter electrode, and glassy carbon electrode working electrode. All electrochemical solutions were purged with $\mathrm{N}_{2}$ for 5 minutes to deoxygenate the system. Solution $\mathrm{CV}$ measurements were carried out with a small molecule concentration of $\sim 0.5 \mathrm{mg} / \mathrm{mL}$ in dichloromethane. The ionization potentials (IP) and electron affinities (EA) were estimated by correlating the $\mathrm{E}_{1 / 2}$ potentials $\left(\mathrm{E}_{\mathrm{ox}} \mathrm{Fc} / \mathrm{Fc}^{+}, \mathrm{E}_{\mathrm{red}} \mathrm{Fc} / \mathrm{Fc}^{+}\right)$to the normal hydrogen electrode (NHE), assuming the IP of $\mathrm{Fc} / \mathrm{Fc}^{+}$to be $4.8 \mathrm{eV}{ }^{1}$

UV-Visible Spectroscopy (UV-Vis): All absorption measurements were recorded using Agilent Technologies Cary $60 \mathrm{UV}-\mathrm{Vis}$ spectrometer at room temperature. All solution UV-Vis experiments were run in $\mathrm{CHCl}_{3}$ using $10 \mathrm{~mm}$ quartz cuvettes. Neat films of pure compounds were prepared by spin-coating $\sim 0.2 \mathrm{~mL}$ from a $1 \% \mathrm{wt} / \mathrm{v} \mathrm{CHCl}_{3}$ solution onto Corning glass micro slides. Prior to use, glass slides were cleaned with soap and water, acetone and isopropanol, and followed by UV/ozone treatment using a Novascan UV/ozone cleaning system. 


\section{$\underline{\text { Experimental }}$}

Synthesis of SePDI-DPP-NPDI: In a $5 \mathrm{~mL}$ pressure vial, SePDI-DPP (150 mg, $0.11 \mathrm{mmol}, 1.0$ eq), 11-bromo-5-hexyl-2,8-bis(1-ethylpropyl)perylene diimide (84mg, $0.12 \mathrm{mmol}, 1.0 \mathrm{eq})$, SiliaCat@ DPP-Pd (10 mol\% Pd to SePDI-DPP), pivalic acid (40 mol\% to DPP), and potassium carbonate (28 mg, $0.51 \mathrm{mmol}, 1.8$ eq.) were added with a stir bar followed by the addition of anhydrous, degassed $N, N^{\prime}$-dimethylacetamide $(2 \mathrm{~mL})$. The reaction mixture was sealed with a Teflon ${ }^{\circledR}$ cap under $\mathrm{N}_{2}$ and heated at $120{ }^{\circ} \mathrm{C}$ in a LabArmor® bead bath for 24 hours. After 24 hours, the reaction mixture was poured into $\mathrm{MeOH}(50 \mathrm{~mL})$ and stirred for 1 hour. The mixture was filtered through celite, rinsing with $\mathrm{MeOH}$ to remove a dark blue filtrate. A dark purple solid was recovered from the celite by washing with $\mathrm{CH}_{2} \mathrm{Cl}_{2}$ and $\mathrm{CHCl}_{3}$. The solvents were removed by rotary evaporation and the solid was isolated by precipitation with $\mathrm{MeOH}$ and vacuum filtration. The crude solid was purified by column chromatography, eluting with a 5:1 $\mathrm{CH}_{2} \mathrm{Cl}_{2}$ :hexanes to separate unreacted SePDI-DPP and then pure $\mathrm{CH}_{2} \mathrm{Cl}_{2}$ to recover the product SePDI-DPP-NPDI (dark purple solid, $153 \mathrm{mg}, 0.080 \mathrm{mmol}, 69 \%$ ).

${ }^{1}$ H NMR (500 MHz, CDCl3, ppm): $\delta 9.43$ (d, br, 2H, $\left.J_{\mathrm{H}-\mathrm{Se}}=28.4 \mathrm{~Hz} ; \mathrm{SePDI}\right), 9.38$ (d, br, 2H, $J_{\mathrm{H}-}$ $\mathrm{Se}=27.0 \mathrm{~Hz}$; SePDI), 9.37 (d, 2H, J=3.8 Hz; Th), 9.30 (d, 2H, J=3.8 Hz; Th), 9.12, (s, 1H; NPDI), 9.06 (s, 1H; NPDI), 8.92 (d, br, 1H, $J_{\mathrm{H}-\mathrm{Se}}=22.5 \mathrm{~Hz}$; SePDI), 8.88 (s, 1H; NPDI), 8.61 (m, br, 2H; NPDI and SePDI), 8.38 (d, 1H, J=8.4 Hz; SePDI), 8.32, (d, 1H, J=8.3 Hz; NPDI), 7.64 (d, 2H, $J=3.9 \mathrm{~Hz}$; Th), 7.58 (d, 2H, J=3.8 Hz; Th), 5.24 (m, br, 4H; N-CH), 4.95 (m, 2H; PDI-N-CH $)$, 4.13 (m, 4H; DPP-N-CH $)$, 2.42-2.21 (m, br, 12H; $\left.\mathrm{CH}_{2}\right), 2.05-1.80$ (m, 12H; $\left.\mathrm{CH}_{2}\right), 1.51-1.06(\mathrm{~m}$, $\left.68 \mathrm{H} ; \mathrm{CH}_{2}\right), 0.99$ (t, 6H, J=7.1 Hz; $\left.\mathrm{CH}_{3}\right), 0.95$ (t, 6H, J=7.1 Hz; $\left.\mathrm{CH}_{3}\right), 0.87$ (t, 3H, J=7.3 Hz; $\mathrm{CH}_{3}$ ), $0.84\left(\mathrm{t}, 6 \mathrm{H}, J=7.1 \mathrm{~Hz} ; \mathrm{CH}_{3}\right), 0.82\left(\mathrm{t}, 6 \mathrm{H}, J=7.1 \mathrm{~Hz} ; \mathrm{CH}_{3}\right), 0.72\left(\mathrm{t}, 3 \mathrm{H}, J=6.8 \mathrm{~Hz} ; \mathrm{CH}_{3}\right), 0.69(\mathrm{t}, 3 \mathrm{H}$, $\left.J=6.9 \mathrm{~Hz} ; \mathrm{CH}_{3}\right)$.

${ }^{13}$ C NMR (125 MHz, CDCl3, ppm): $\delta$ 161.5, 161.5, 148.2, 148.0, 140.0, 139.4, 137.3, 135.2, $132.8,132.6,132.2$, 132.1, 131.9, 129.1, 128.8, 128.5, 128.2, 126.9, 126.7, 126.1, 125.8, 125.1, 125.0, 123.2, 123.1, 120.0, 119.9, 108.9, 108.7, 47.2, 42.7, 42.6, 32.5, 32.5, 31.9, 31.9, 31.8, 31.8, $31.7,31.7,31.5,30.3,29.3,29.3,29.2,27.1,27.0,26.8,26.8,25.3,22.8,22.7,22.7,22.7,22.6$, $14.3,14.2,14.2,14.2,14.2,14.1,11.6,11.6$.

Tabulated ${ }^{13} \mathrm{C}$ signals: 63; expected ${ }^{13} \mathrm{C}$ signals: 102 .

HRMS (MALDI-TOF): m/z 1924.8524 (M+H), 1946.8967 (M+Na). calcd. 1923.8408.

CHN: Calculated: C, 72.30; H, 6.76; N, 65.09. Found: C, 72.39; H, 6.64; N, 5.13.

Synthesis of SePDI-DPP and SePDI-DPP-SePDI: In a $5 \mathrm{~mL}$ pressure vial, 2,5-bis(1-octyl)-3,6di(thiophen-2- yl)diketopyrrolopyrrole $(100 \mathrm{mg}, 0.19 \mathrm{mmol}, 1.0 \mathrm{eq}),[1,12-b, c, d]$ selenophene6-bromoperylene diimide (410 mg, $0.48 \mathrm{mmol}, 2.5 \mathrm{eq})$, SiliaCat@ DPP-Pd (10 mol\% Pd to DPP), pivalic acid (40 mol\% to DPP), and potassium carbonate ( $75 \mathrm{mg}, 0.54 \mathrm{mmol}, 2.8 \mathrm{eq}$.) were added with a stir bar followed by the addition of anhydrous, degassed $N, N$ '-dimethylacetamide ( 5 $\mathrm{mL}$ ). The reaction mixture was sealed with a Teflon ${ }^{\circledR}$ cap under $\mathrm{N}_{2}$ and heated at $80{ }^{\circ} \mathrm{C}$ in a LabArmor® bead bath for 24 hours. After 24 hours, the reaction mixture was poured into $\mathrm{MeOH}$ $(50 \mathrm{~mL})$ and stirred for 1 hour. The mixture was filtered through celite, rinsing with $\mathrm{MeOH}$ to 
remove a dark blue filtrate. A dark purple solid was recovered from the celite by washing with $\mathrm{CH}_{2} \mathrm{Cl}_{2}$ and $\mathrm{CHCl}_{3}$. The solvents were removed by rotary evaporation and the solid was isolated by precipitation with $\mathrm{MeOH}$ and vacuum filtration. The crude solid was purified by column chromatography, eluting with a $\mathrm{CH}_{2} \mathrm{Cl}_{2} /$ hexanes gradient from $3: 2$ to $3: 1 \mathrm{CH}_{2} \mathrm{Cl}_{2}$ :hexanes to separate unreacted starting materials and recover monosubstituted side-product SePDI-DPP (dark purple solid) and then pure $\mathrm{CH}_{2} \mathrm{Cl}_{2}$ to recover the target product SePDI-DPP-SePDI (dark purple solid, $98.0 \mathrm{mg}, 0.047 \mathrm{mmol}, 25 \%)$.

${ }^{1}$ H NMR SePDI-DPP (500 MHz, CDCl3, ppm): $\delta 9.42\left(\mathrm{~d}, \mathrm{br}, 1 \mathrm{H}, J_{\mathrm{H}-\mathrm{Se}}=29.1 \mathrm{~Hz} ; \mathrm{SePDI}\right), 9.36$ (d, br, $1 \mathrm{H}, J_{\mathrm{H}-\mathrm{Se}}=26.7 \mathrm{~Hz}$; SePDI), $9.22(\mathrm{~d}, 1 \mathrm{H}, J=3.8 \mathrm{~Hz}$; Th), 9.01 (dd, $1 \mathrm{H}, J=3.8,1.1 \mathrm{~Hz}$; Th), $8.90\left(\mathrm{~d}, 1 \mathrm{H}, J_{\mathrm{H}-\mathrm{Se}}=22.0 \mathrm{~Hz}\right.$; SePDI), $8.58\left(\mathrm{dd}, 2 \mathrm{H}, J_{\mathrm{H}-\mathrm{Se}}=26.7 \mathrm{~Hz}, J_{\mathrm{H}-\mathrm{H}}=8.5 \mathrm{~Hz}, \mathrm{SePDI}\right), 8.36(\mathrm{~d}$, $1 \mathrm{H}, J=8.4 \mathrm{~Hz}$; SePDI), 7.70 (dd, 1H, J=5.0, $1.0 \mathrm{~Hz}$; Th), 7.53 (d, $1 \mathrm{H} \mathrm{J}=3.9 \mathrm{~Hz} ; \mathrm{Th}), 7.32$ (dd, $1 \mathrm{H}$, $J=5.0,3.9 \mathrm{~Hz} ; \mathrm{Th}), 5.26(\mathrm{~m}, 2 \mathrm{H} ; \mathrm{N}-\mathrm{CH}), 4.12\left(\mathrm{t}, 2 \mathrm{H} ; \mathrm{N}_{-}-\mathrm{CH}_{2}\right), 4.07\left(\mathrm{t}, 2 \mathrm{H} ; \mathrm{N}-\mathrm{CH}_{2}\right), 2.28(\mathrm{~m}, \mathrm{br}$, $\left.4 \mathrm{H} ; \mathrm{CH}_{2}\right), 1.89$ (m, 4H; $\left.\mathrm{CH}_{2}\right), 1.78\left(\mathrm{~m}, 4 \mathrm{H} ; \mathrm{CH}_{2}\right), 1.49-1.06$ (m; 44H, $\left.\mathrm{CH}_{2}\right), 0.88$ (t, $3 \mathrm{H}, J=6.9 \mathrm{~Hz}$; $\left.\mathrm{CH}_{3}\right), 0.83\left(\mathrm{t}, 6 \mathrm{H}, J=7.1 \mathrm{~Hz} ; \mathrm{CH}_{3}\right), 0.81\left(\mathrm{t}, 6 \mathrm{H}, J=7.0 \mathrm{~Hz} ; \mathrm{CH}_{3}\right), 0.70$ (t, $3 \mathrm{H}, J=6.9 \mathrm{~Hz} ; \mathrm{CH}_{3}$ ).

${ }^{1} \mathbf{H}$ NMR SePDI-DPP-SePDI (500 MHz, $\left.\mathbf{C D C l}_{3}, \mathbf{p p m}\right): \delta 9.43\left(\mathrm{~d}, \mathrm{br}, 2 \mathrm{H}, J_{\mathrm{H}-\mathrm{Se}}=27.4 \mathrm{~Hz}\right.$; SePDI), 9.38 (d, br, 2H, $\left.J_{\mathrm{H}-\mathrm{Se}}=26.9 \mathrm{~Hz} ; \mathrm{SePDI}\right), 9.30(\mathrm{~d}, 2 \mathrm{H}, J=3.8 \mathrm{~Hz} ; \mathrm{Th}), 8.92\left(\mathrm{~d}, 2 \mathrm{H}, J_{\mathrm{H}-\mathrm{Se}}=22.2\right.$ $\mathrm{Hz}$; SePDI), $8.60\left(\mathrm{dd}, 2 \mathrm{H}, J_{\mathrm{H}-\mathrm{Se}}=26.4 \mathrm{~Hz}, J_{\mathrm{H}-\mathrm{H}}=7.1 \mathrm{~Hz}\right.$; SePDI), 8.38 (d, 2H, $\left.J=8.4 \mathrm{~Hz}, \mathrm{SePDI}\right)$,

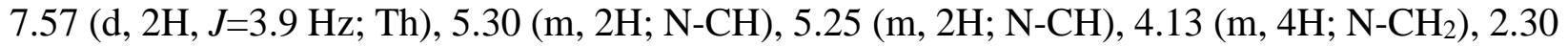
(m, br, 8H; $\mathrm{CH}_{2}$ ), 1.94-1.80 (m, 12H; $\left.\mathrm{CH}_{2}\right), 1.41-1.09$ (m, 68H; $\left.\mathrm{CH}_{2}\right), 0.84$ (t, $12 \mathrm{H}, J=7.1 \mathrm{~Hz}$; $\left.\mathrm{CH}_{3}\right), 0.82\left(\mathrm{t}, 12 \mathrm{H}, J=7.1 \mathrm{~Hz} ; \mathrm{CH}_{3}\right), 0.72\left(\mathrm{t}, 6 \mathrm{H}, J=6.9 \mathrm{~Hz} ; \mathrm{CH}_{3}\right)$.

${ }^{13}$ C NMR SePDI-DPP-SePDI (125 MHz, CDCl3, ppm): $\delta$ 165.2, 164.7, 163.5, 161.5, 148.3, 141.0, 139.7, 137.3, 134.7, 134.4, 134.3, 133.3, 132.8, 132.2, 132.1, 128.8, 128.5, 126.9, 126.7 , $126.2,125.8,122.5,122.4,108.9,55.3,55.1,42.7,32.5,32.5,31.9,31.8,29.3,29.2,27.0,26.8$, $26.8,22.8,22.7,22.7,14.2,14.2,14.1$.

Tabulated ${ }^{13} \mathrm{C}$ signals: 42 ; expected ${ }^{13} \mathrm{C}$ signals: 51 .

HRMS SePDI-DPP-SePDI (MALDI-TOF): $\mathrm{m} / \mathrm{z}$ 2072.7673，2095.8347 (M+Na). calcd. 2072.8403 .

CHN SePDI-DPP-SePDI: Calculated: C, 70.70; H, 6.81; N, 4.05. Found: C, 70.73; H, 6.75; N, 3.98 . 


\section{$\underline{\text { Solution NMR Spectra }}$}

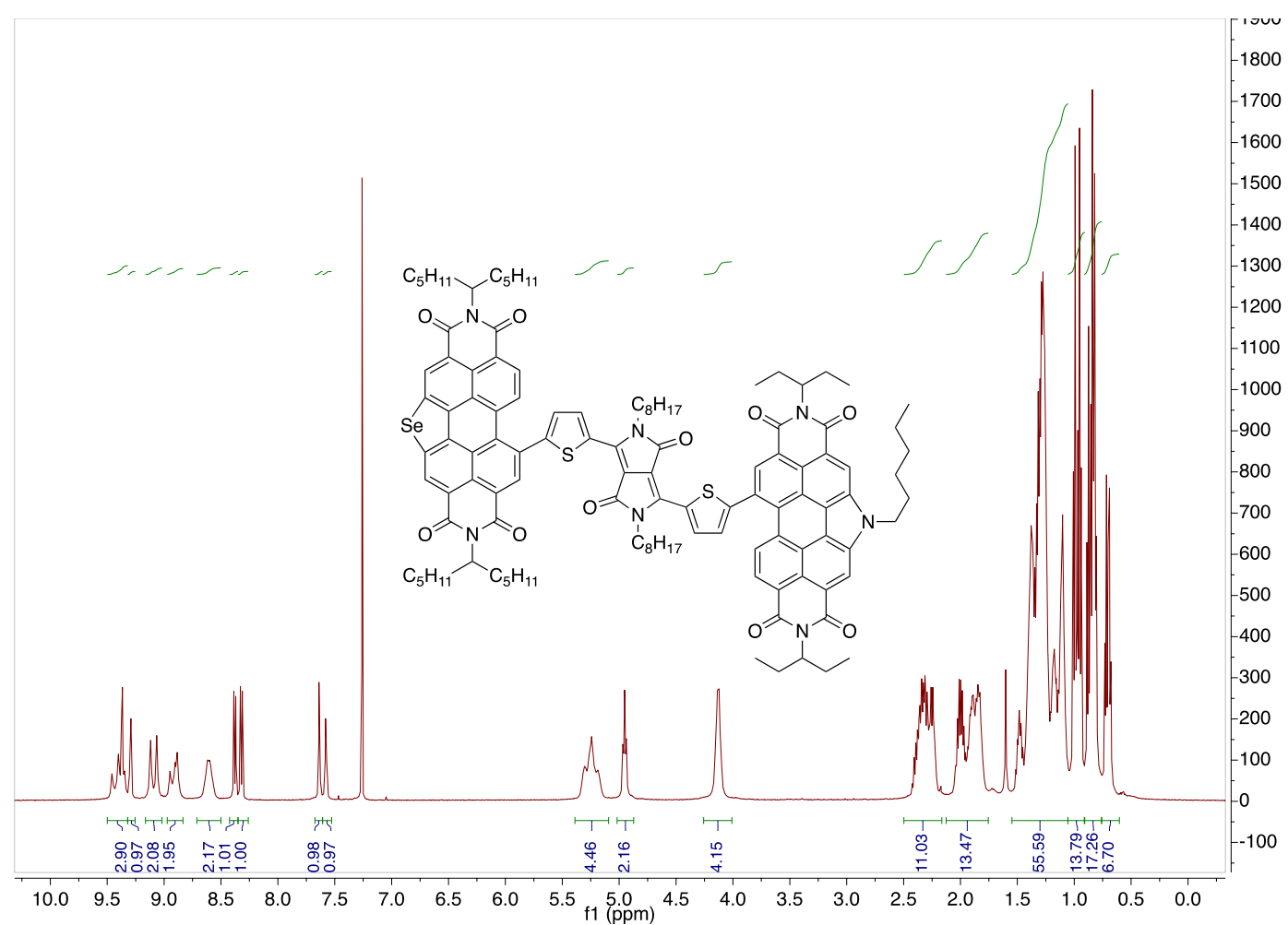

Figure S1. ${ }^{13} \mathrm{H}$ NMR spectrum of SePDI-DPP-NPDI in $\mathrm{CDCl}_{3}$.

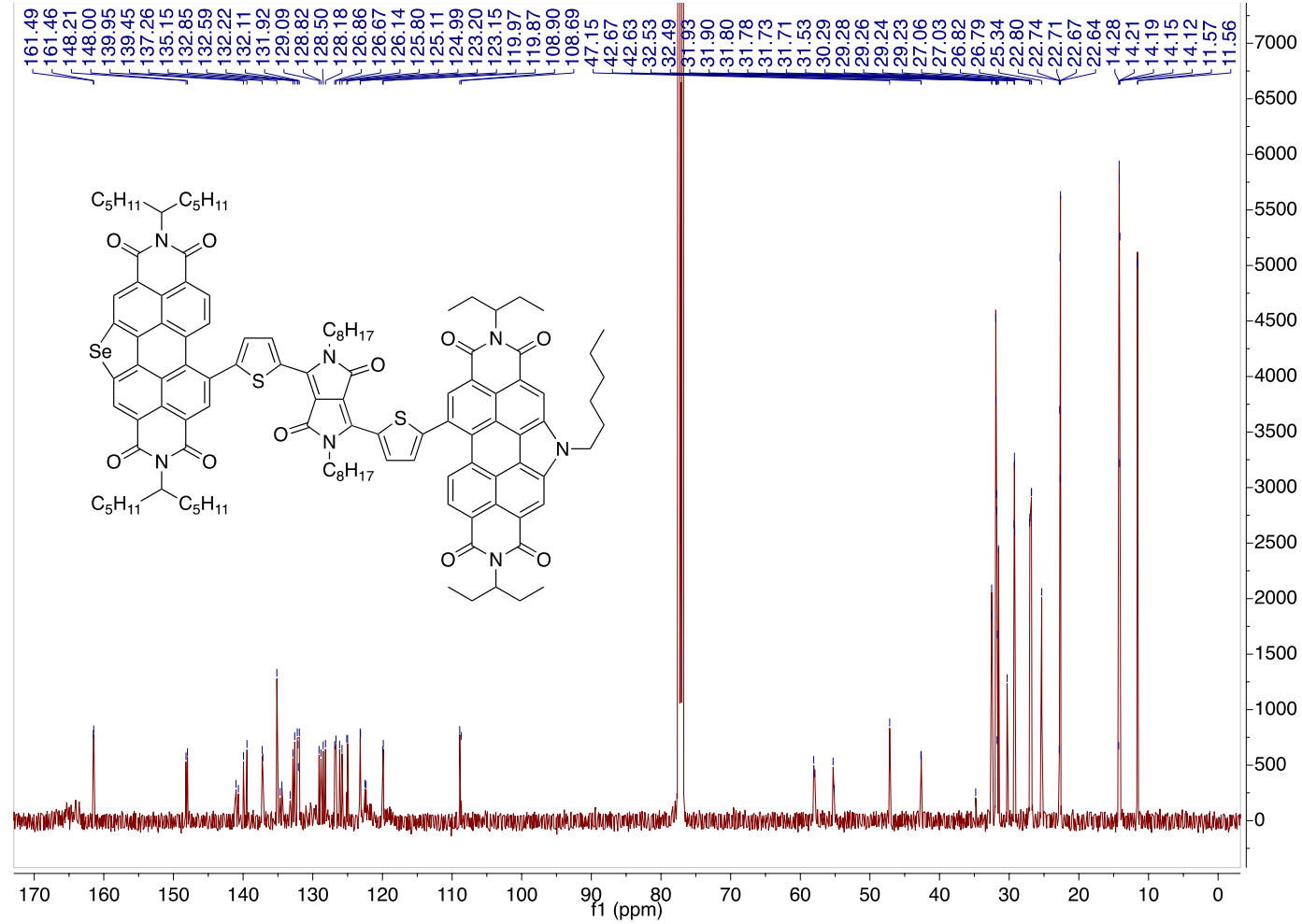

Figure S2. ${ }^{13} \mathrm{C}$ NMR spectrum of SePDI-DPP-NPDI in $\mathrm{CDCl}_{3}$. 


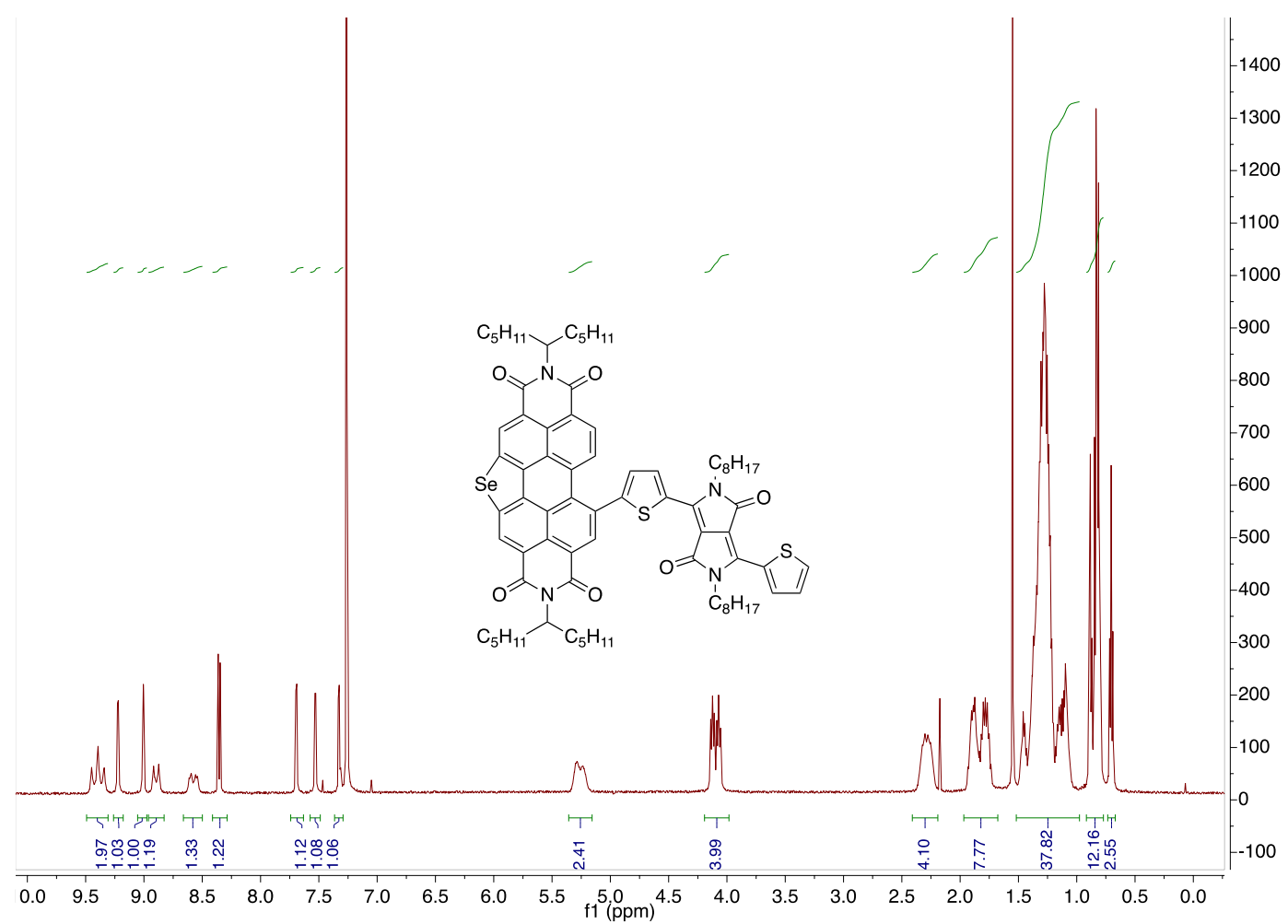

Figure S3. ${ }^{1} \mathrm{H}$ NMR spectrum of SePDI-DPP in $\mathrm{CDCl}_{3}$.

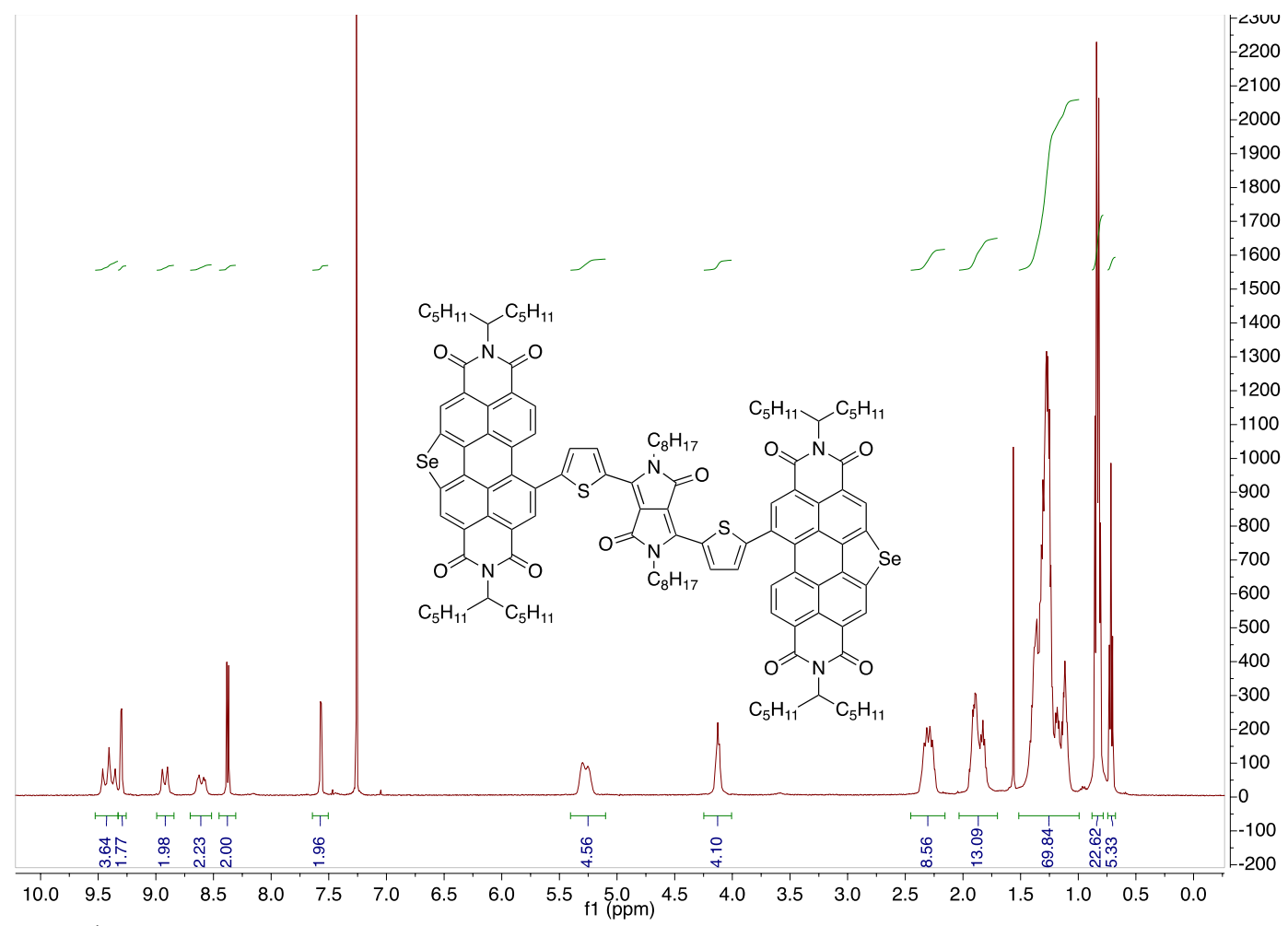

Figure S4. ${ }^{1} \mathrm{H}$ NMR spectrum of SePDI-DPP-SePDI in $\mathrm{CDCl}_{3}$. 


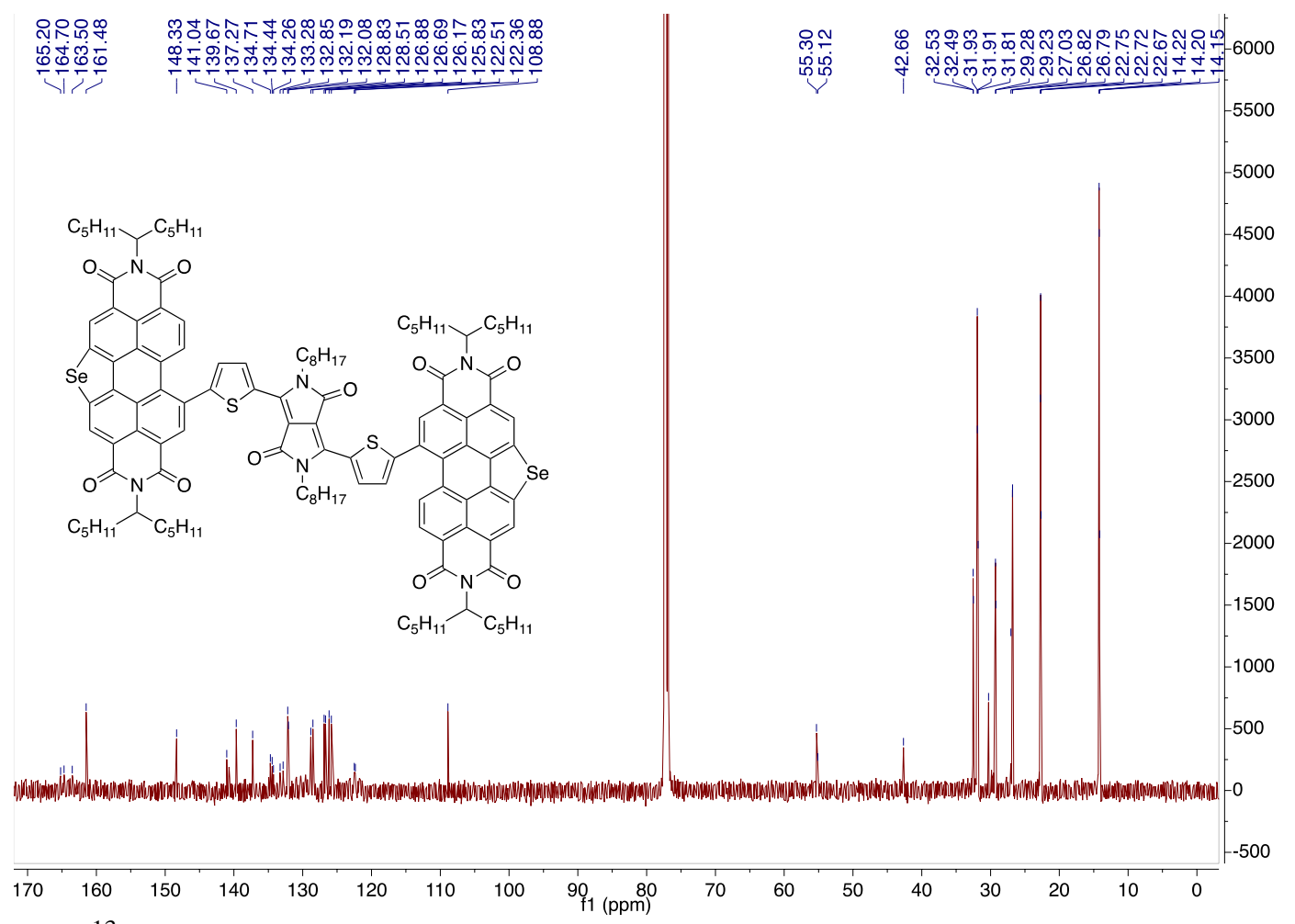

Figure S5. ${ }^{13} \mathrm{C}$ NMR spectrum of SePDI-DPP-SePDI in $\mathrm{CDCl}_{3}$. 
Mass Spectrometry (MALDI-TOF)

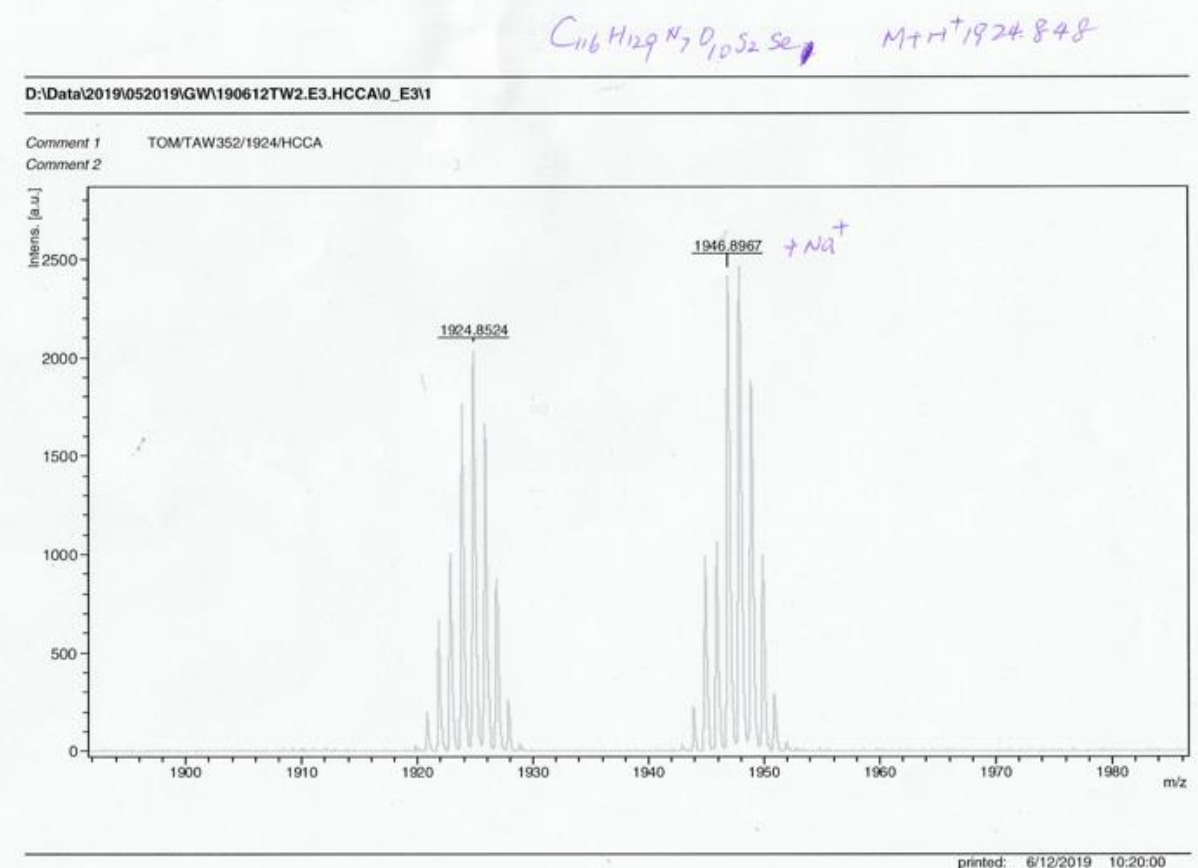

Figure S6. MALDI-TOF of SePDI-DPP-NPDI.

$\mathrm{C}_{122} \mathrm{H}_{120 \mathrm{~N}} \mathrm{OO}_{10} \mathrm{~S}_{2} \mathrm{Se}_{2} \mathrm{M}+\mathrm{Nin}^{+} 2095.8295$

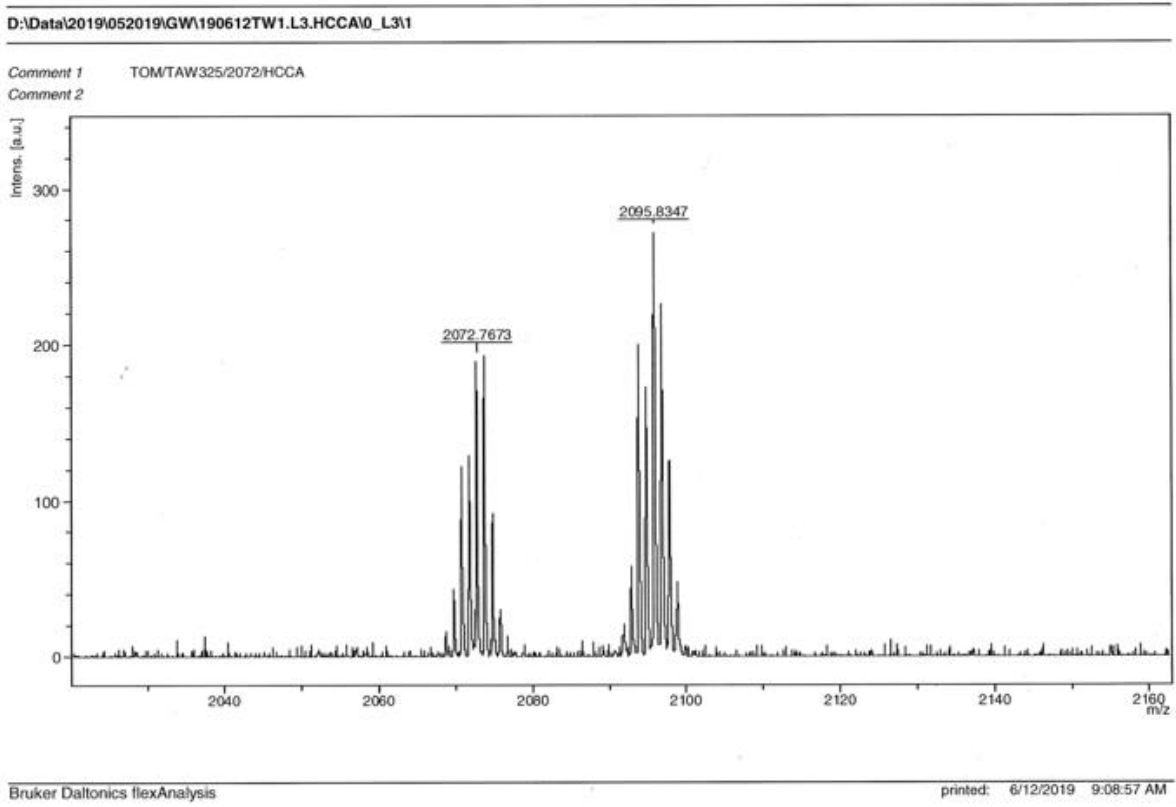

Figure S7. MALDI-TOF of SePDI-DPP-SePDI. 


\section{Elemental Analysis}

\begin{tabular}{|c|c|c|c|c|c|c|c|c|c|}
\hline \multicolumn{2}{|c|}{$\begin{array}{l}\text { University of Calgary } \\
\text { Department of Chemistry }\end{array}$} & \multirow{2}{*}{$\begin{array}{l}\text { EA } \\
\text { Group: }\end{array}$} & \multirow{2}{*}{$\begin{array}{l}\text { Oate: } \\
\text { GW }\end{array}$} & \multirow[t]{2}{*}{ 5/29/2019 } & \multicolumn{2}{|c|}{$\begin{array}{l}\text { University of Calgary } \\
\text { Department of Chemistry }\end{array}$} & \multirow{2}{*}{$\begin{array}{l}\text { EA } \\
\text { Grous: }\end{array}$} & \multirow{2}{*}{$\begin{array}{l}\text { Date: } \\
\text { GW }\end{array}$} & \multirow[t]{2}{*}{ \$/29/2019 } \\
\hline Name: & ton & & & & Name: & TOM & & & \\
\hline Sample: & TAW3:1 1 & Weight in & & 1.579 & Sample: & TAW352:2 & Weight I & & 1.325 \\
\hline NC (Actua) & $n .37$ & NC Theo & ectecal!! & $n .40$ & NC (Actual): & $n .39$ & NC (Ther & ecticall: & $n=0$ \\
\hline Nin (Actual): & 6.5 & Nir (thees & etical: & 6.76 & SH (Actua): & 6.64 & SH (The & etical]: & 6.7 \\
\hline NN (Actual): & 5.00 & NN Thes & etical: & 5.09 & SN (Actua): & 5.13 & NN The & etical): & 5.09 \\
\hline
\end{tabular}

Figure S8. Elemental analysis results of SePDI-DPP-NPDI.

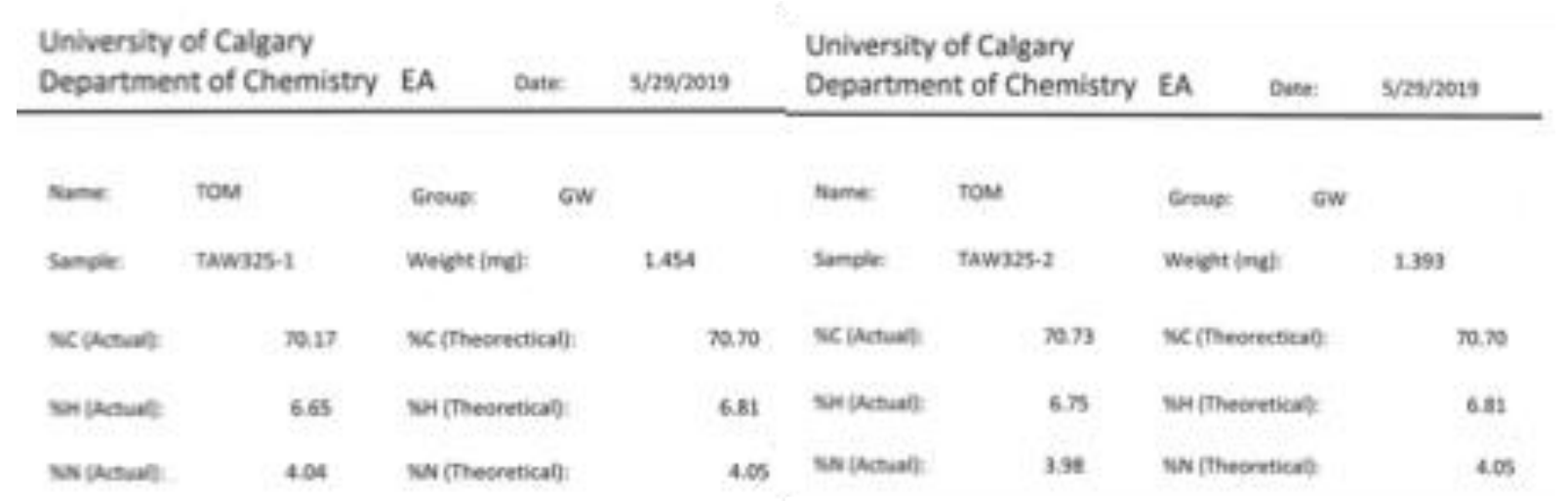

Figure S9. Elemental analysis results of SePDI-DPP-SePDI. 


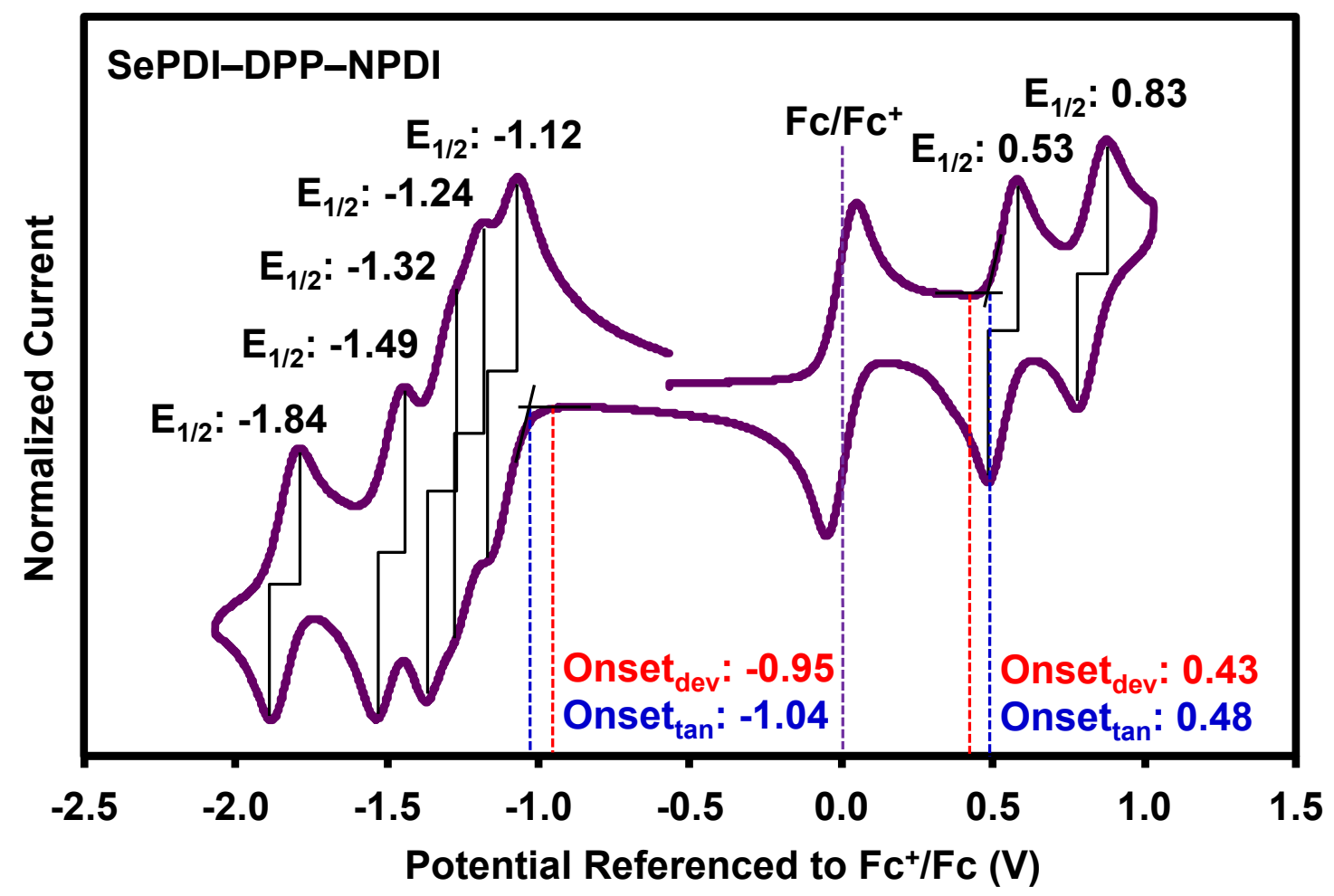

Figure S10. Cyclic voltammogram of SePDI-DPP-NPDI measured at $100 \mathrm{mV} / \mathrm{s}$ in $\mathrm{CH}_{2} \mathrm{Cl}_{2}$.

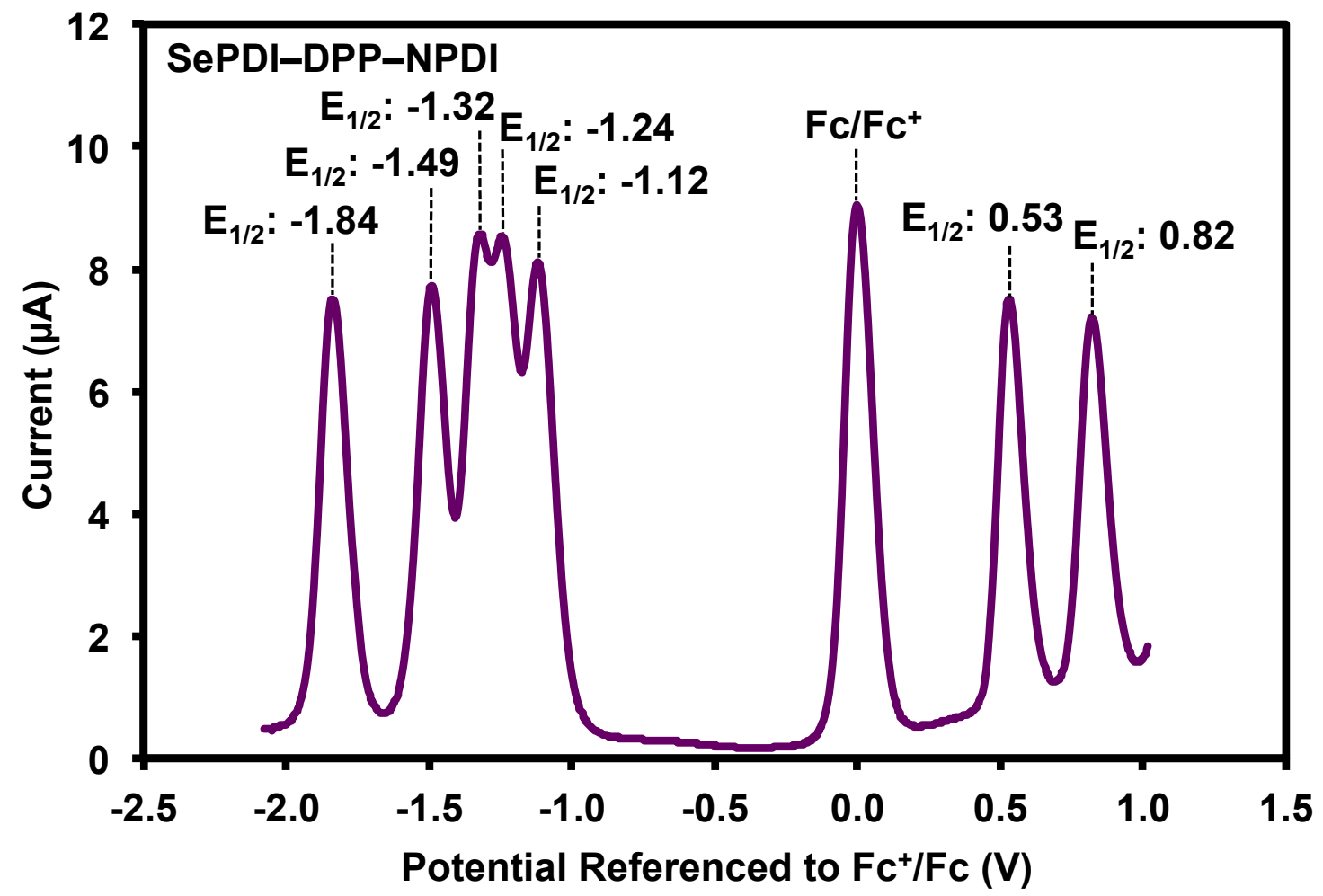

Figure S11. Differential pulse voltammogram of SePDI-DPP-NPDI measured in $\mathrm{CH}_{2} \mathrm{Cl}_{2}$. 


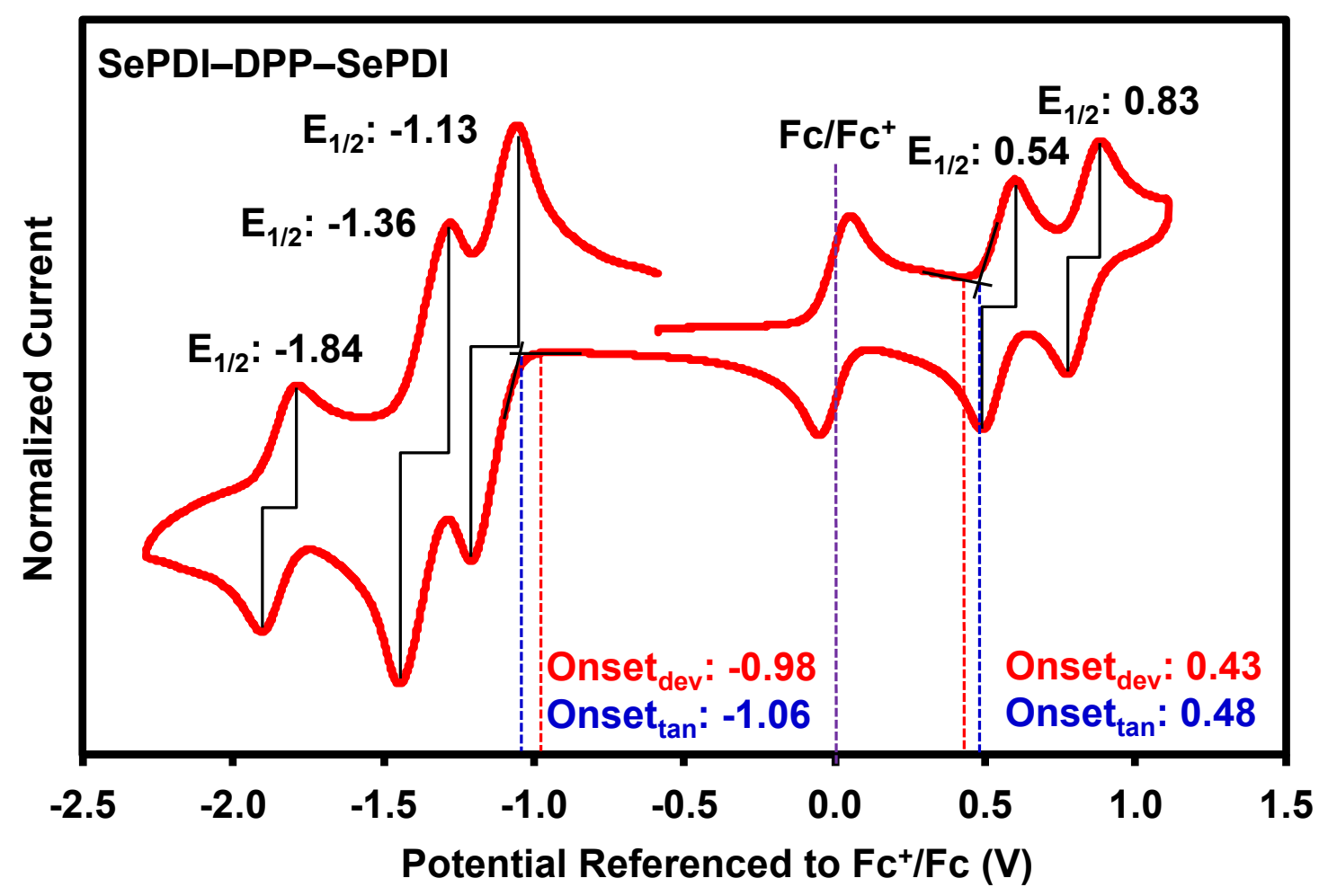

Figure S12. Cyclic voltammogram of SePDI-DPP-SePDI measured at $100 \mathrm{mV} / \mathrm{s}$ in $\mathrm{CH}_{2} \mathrm{Cl}_{2}$.

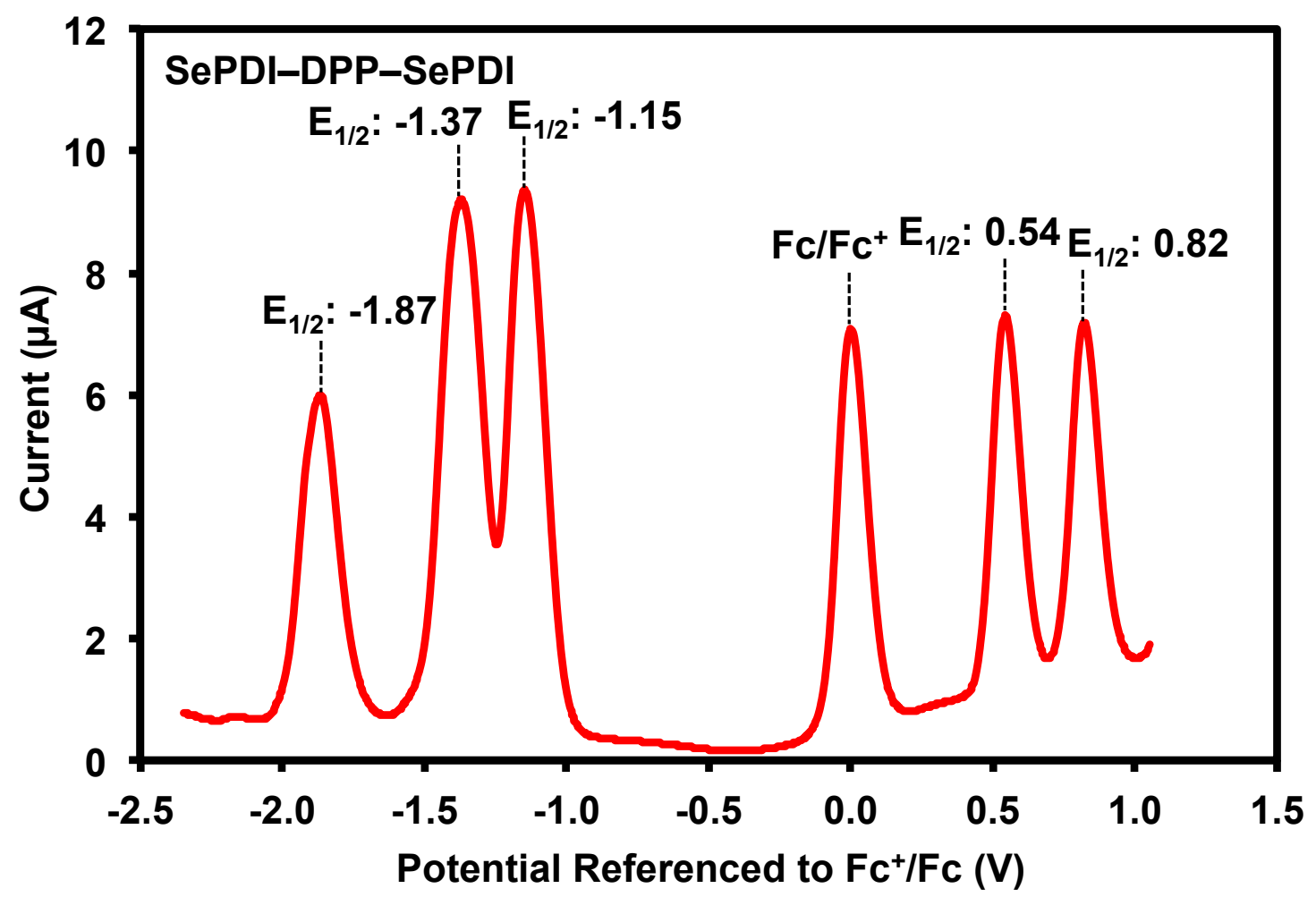

Figure S13. Differential pulse voltammogram of SePDI-DPP-SePDI measured in $\mathrm{CH}_{2} \mathrm{Cl}_{2}$. 


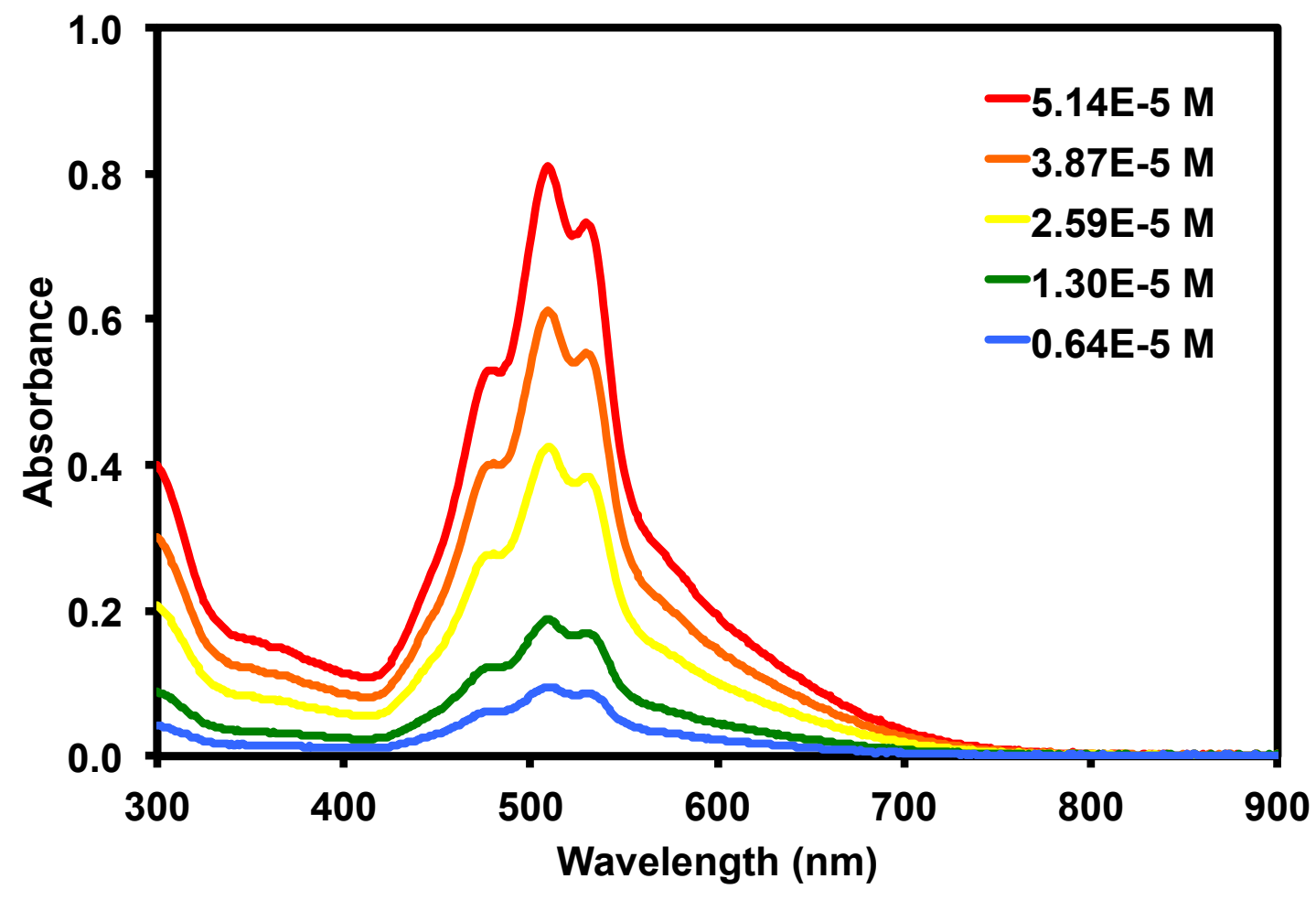

Figure S14. Solution absorption spectra for SePDI-DPP-SePDI in $\mathrm{CHCl}_{3}$.

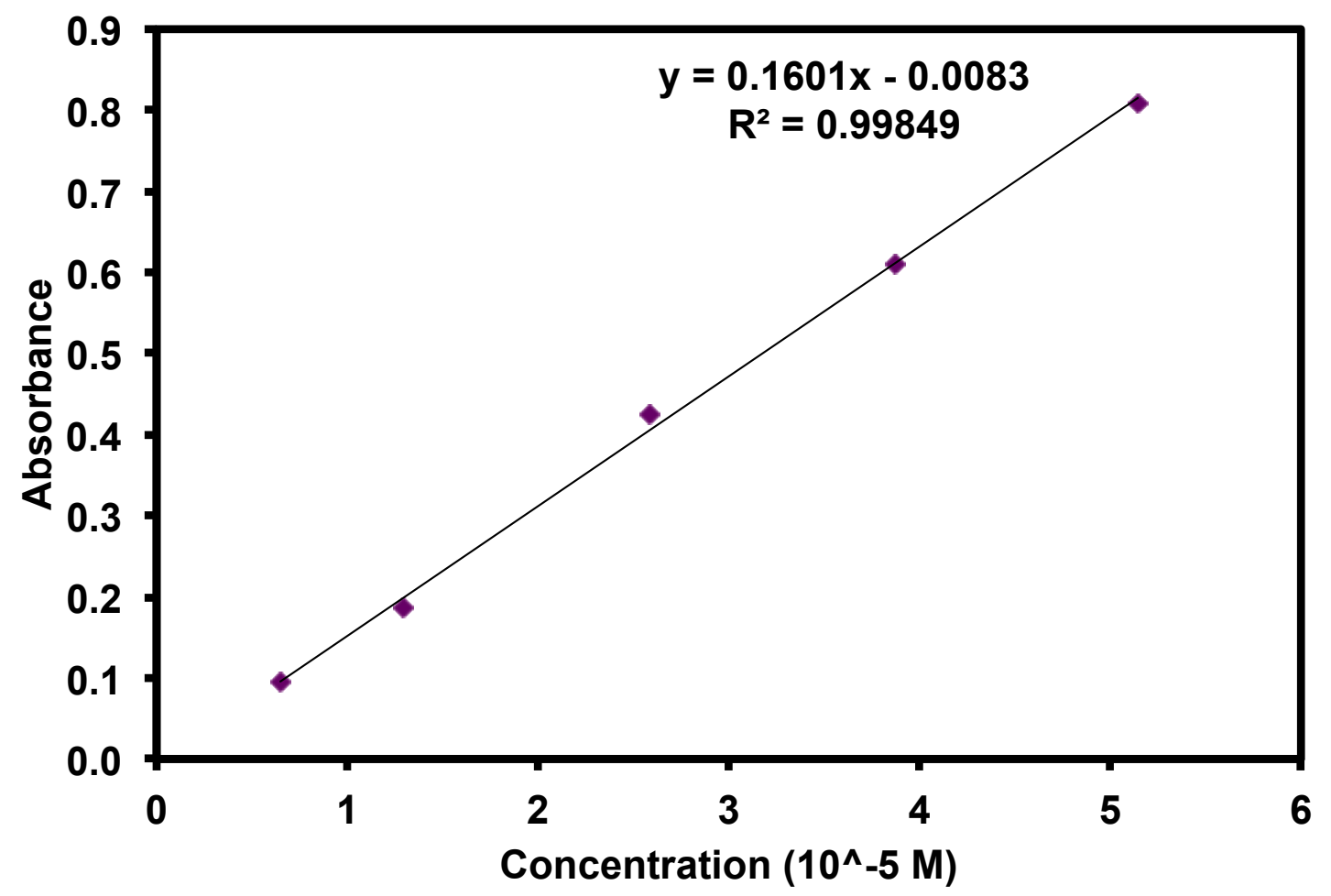

Figure S15: Absorbance versus concentration profile for SePDI-DPP-SePDI. 


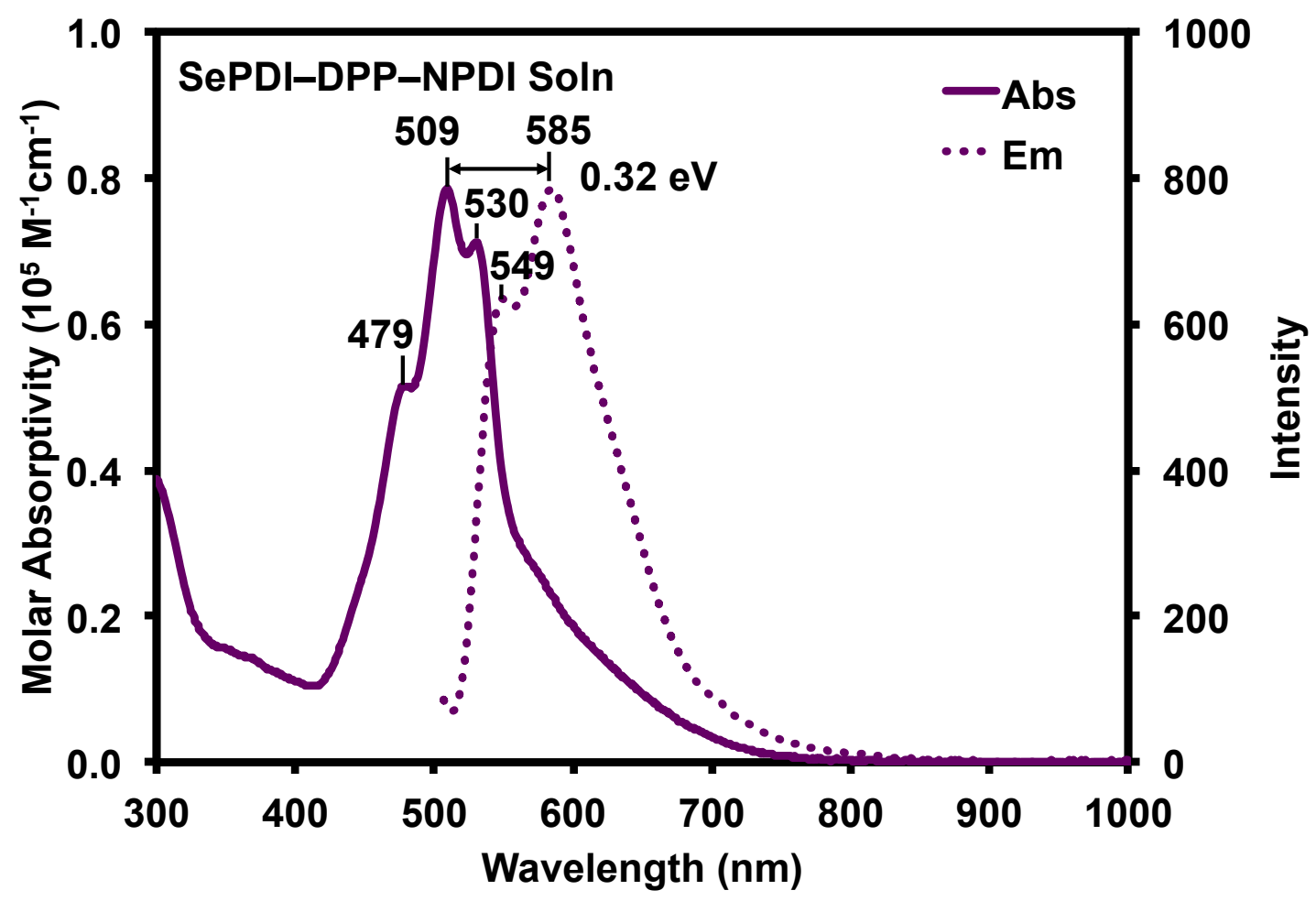

Figure S16: Absorption and emission spectra for SePDI-DPP-SePDI measured in $\mathrm{CHCl}_{3}$.

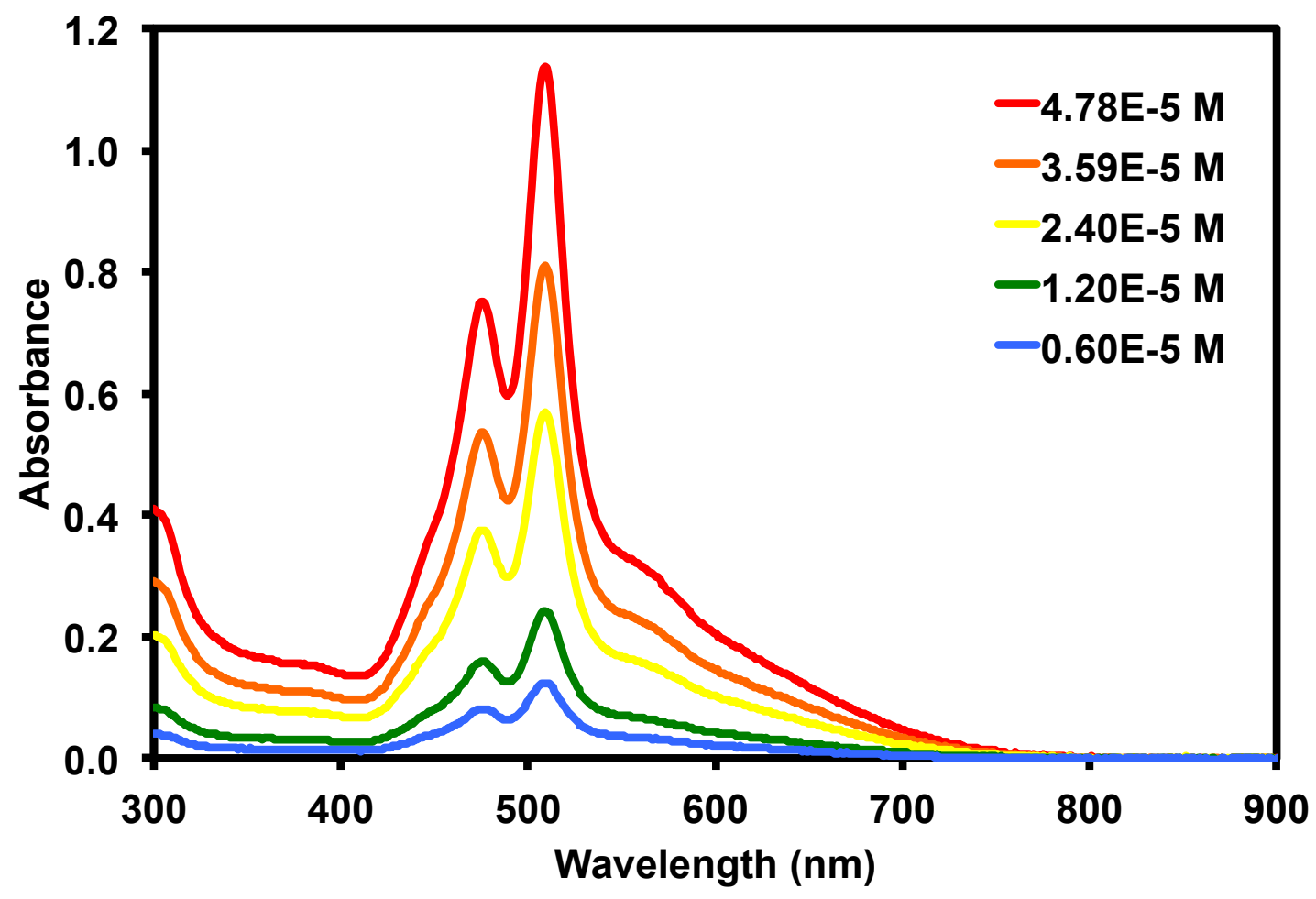

Figure S17. Solution absorption spectra for SePDI-DPP-SePDI in $\mathrm{CHCl}_{3}$. 


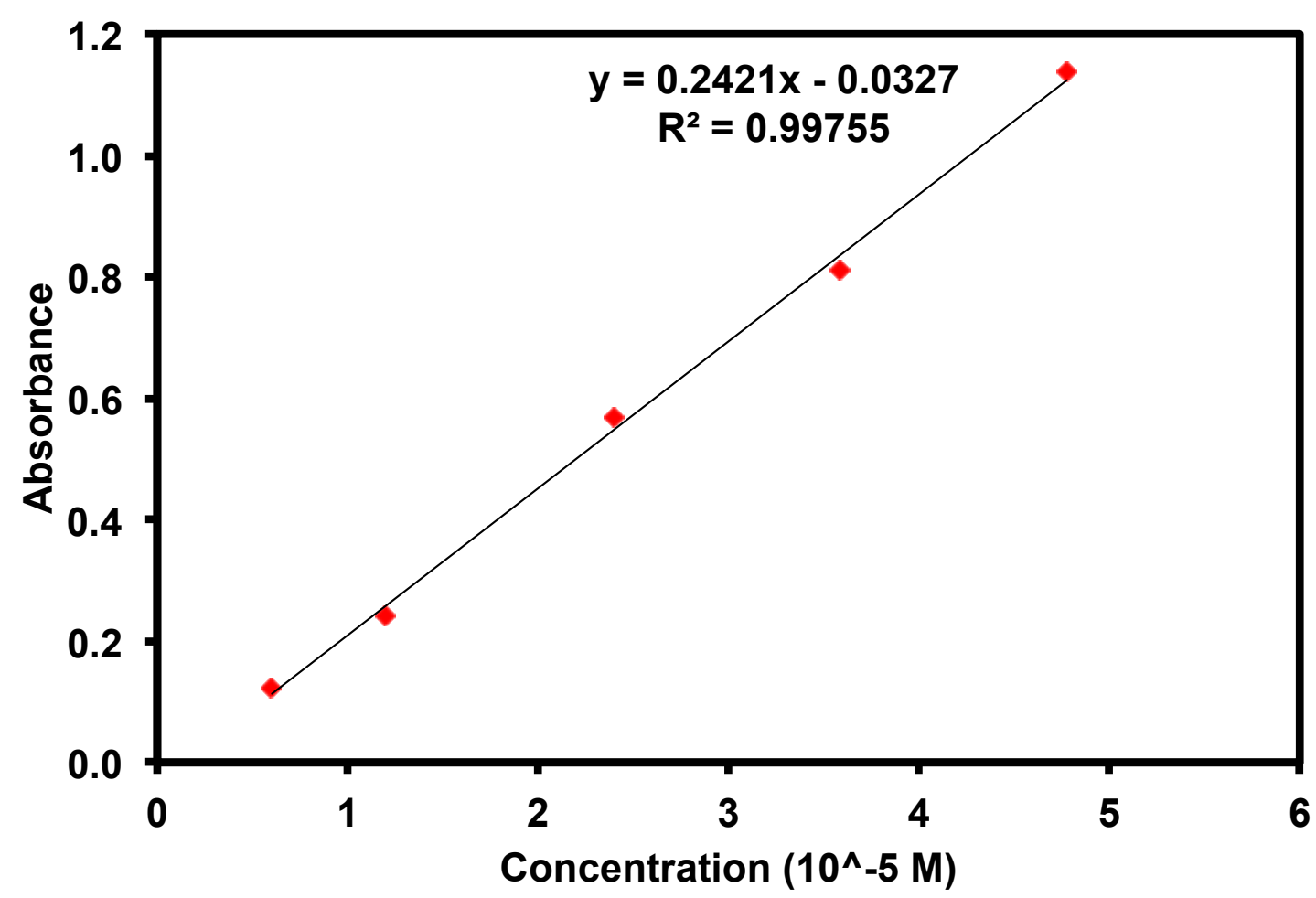

Figure S18: Absorbance versus concentration profile for SePDI-DPP-SePDI.

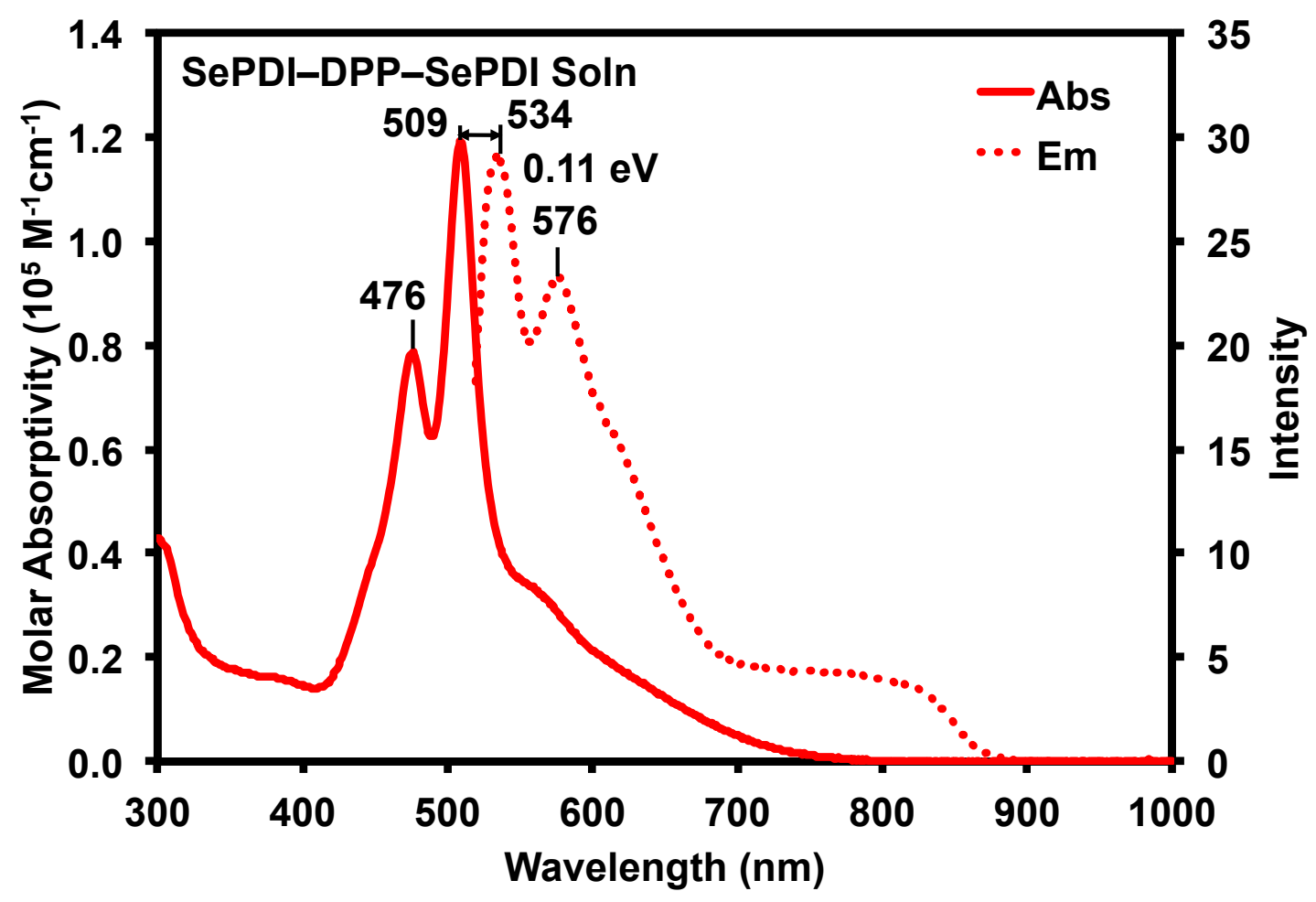

Figure S19: Absorption and emission spectra for SePDI-DPP-SePDI measured in $\mathrm{CHCl}_{3}$. 

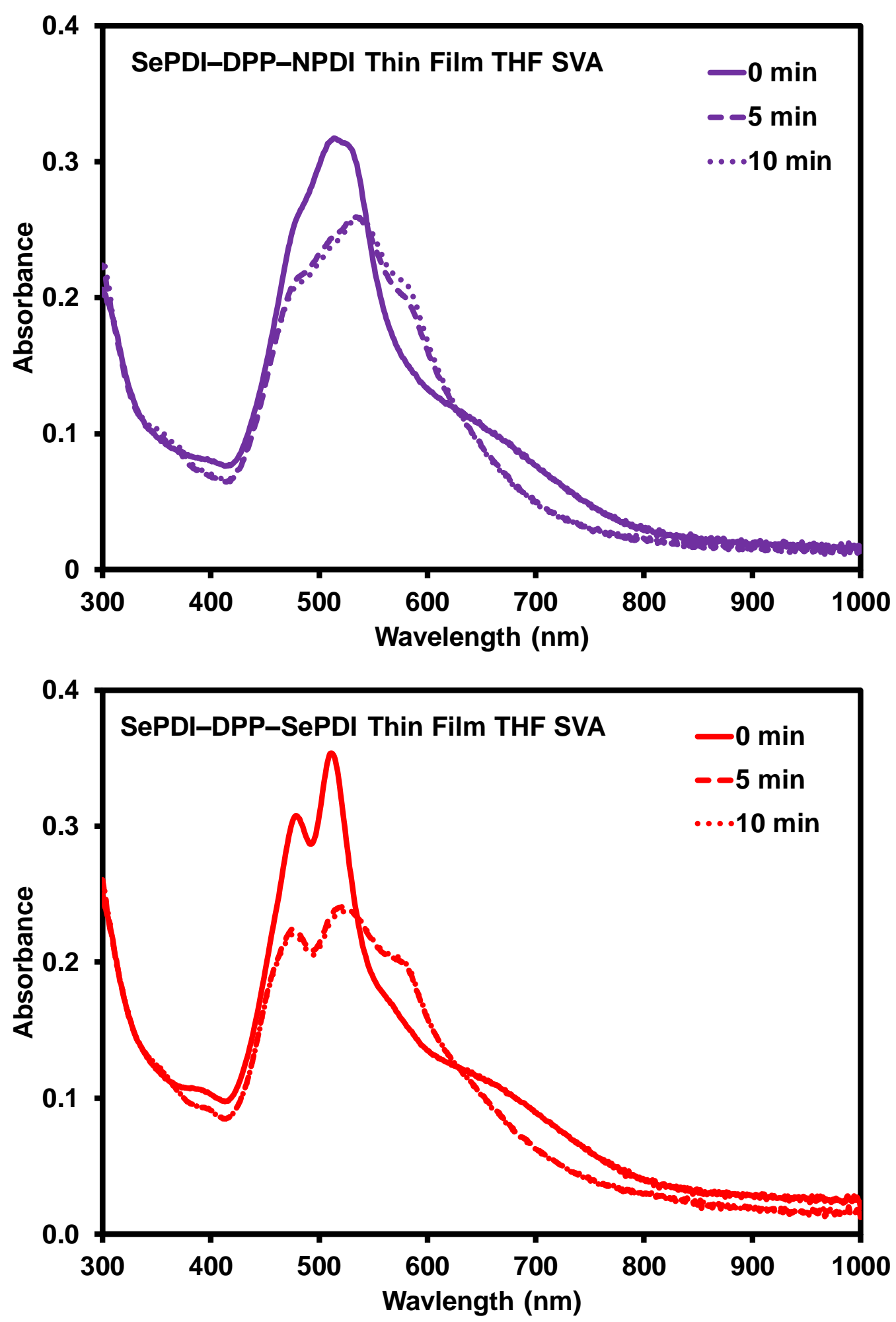

Figure S20: Thin film absorption profiles of SePDI-DPP-NPDI (top) and SePDI-DPP-SePDI (bottom) showing effects of THF solvent vapour annealing up to $10 \mathrm{~min}$. Thin films were spuncast from $1.0 \mathrm{wt} / \mathrm{v} \% \mathrm{CHCl}_{3}$ solutions. 


\section{Density Functional Theory Calculations}

Table S1. Summary of predicted optical transitions for SePDI-DPP-SePDI and SePDI-DPPNPDI.

\begin{tabular}{|c|c|c|c|c|c|}
\hline Compound & State & $E_{\text {opt }}(\mathrm{eV})$ & $\lambda(\mathbf{n m})$ & f & Composition \\
\hline \multirow[t]{6}{*}{ SePDI-DPP-NPDI } & $S_{1}$ & 1.42 & 872 & 0.180 & $\mathrm{H} \rightarrow \mathrm{L}(99 \%)$ \\
\hline & $\mathrm{S}_{2}$ & 1.59 & 778 & 0.127 & $\mathrm{H} \rightarrow \mathrm{L}+1(99 \%)$ \\
\hline & $\mathrm{S}_{3}$ & 2.23 & 557 & 0.820 & $\begin{array}{l}\mathrm{H} \rightarrow \mathrm{L}+2(84 \%) \\
\mathrm{H}-1 \rightarrow \mathrm{L}+1(6 \%) \\
\mathrm{H}-2 \rightarrow \mathrm{L}(5 \%) \\
\mathrm{H}-1 \rightarrow \mathrm{L}(3 \%)\end{array}$ \\
\hline & $\mathrm{S}_{5}$ & 2.44 & 506 & 0.649 & $\begin{array}{l}\mathrm{H}-2 \rightarrow \mathrm{L}(50 \%) \\
\mathrm{H}-1 \rightarrow \mathrm{L}=1(48 \%)\end{array}$ \\
\hline & $\mathrm{S}_{6}$ & 2.47 & 501 & 0.339 & $\begin{array}{l}\mathrm{H}-1 \rightarrow \mathrm{L}+1(44 \%) \\
\mathrm{H}-2 \rightarrow \mathrm{L}(43 \%) \\
\mathrm{H} \rightarrow \mathrm{L}+2(12 \%)\end{array}$ \\
\hline & $\mathrm{S}_{9}$ & 2.79 & 445 & 0.115 & $\mathrm{H}-4 \rightarrow \mathrm{L}(91 \%)$ \\
\hline \multirow[t]{6}{*}{ SePDI-DPP-SePDI } & $\mathrm{S}_{1}$ & 1.42 & 870 & 0.282 & $\mathrm{H} \rightarrow \mathrm{L}(99 \%)$ \\
\hline & $\mathrm{S}_{3}$ & 2.22 & 559 & 0.858 & $\begin{array}{l}\mathrm{H} \rightarrow \mathrm{L}+2(88 \%) \\
\mathrm{H}-2 \rightarrow \mathrm{L}(7 \%) \\
\mathrm{H}-1 \rightarrow \mathrm{L}+1(4 \%)\end{array}$ \\
\hline & $\mathrm{S}_{4}$ & 2.41 & 516 & 0.387 & $\mathrm{H}-1 \rightarrow \mathrm{L}(98 \%)$ \\
\hline & $\mathrm{S}_{6}$ & 2.48 & 500 & 0.268 & $\begin{array}{l}\mathrm{H}-1 \rightarrow \mathrm{L}+1(87 \%) \\
\mathrm{H} \rightarrow \mathrm{L}+2(7 \%) \\
\mathrm{H}-2 \rightarrow \mathrm{L}(4 \%)\end{array}$ \\
\hline & $\mathrm{S}_{7}$ & 2.50 & 495 & 0.282 & $\mathrm{H}-2 \rightarrow \mathrm{L}+1(98 \%)$ \\
\hline & $\mathrm{S}_{9}$ & 2.78 & 445 & 0.199 & $\begin{array}{l}\mathrm{H}-4 \rightarrow \mathrm{L}(55 \%) \\
\mathrm{H}-3 \rightarrow \mathrm{L}+1(37 \%)\end{array}$ \\
\hline
\end{tabular}




\section{Organic Photovoltaics}

Organic Photovoltaic (OPV) Devices: Devices were fabricated using ITO-coated glass substrates cleaned by sequentially ultra-sonicating with detergent and de-ionized water, acetone, and isopropanol followed by exposure to UV/ozone for $30 \mathrm{~min}$. ZnO was subsequently deposited as a sol-gel precursor solution in a $\mathrm{N}_{2}$ purge box following the method of Sun et al. ${ }^{2}$ The room temperature solution was spin-coated at a speed of $5000 \mathrm{rpm}$ and then annealed at $200{ }^{\circ} \mathrm{C}$ for at least $20 \mathrm{~min}$. Active layer solutions of PTB7-Th, SePDI-DPP-NPDI, and SePDI-DPP-SePDI were prepared in air with a total concentration of $10 \mathrm{mg} / \mathrm{mL}$ in Chloroform $(\mathrm{CF})$. Solutions were stirred for $1 \mathrm{~h}$ at $50{ }^{\circ} \mathrm{C}$. Active layer materials were combined in a 3:7 donor/acceptor weight ratio. The active layer solution was coated at room temperature at a speed of $1500 \mathrm{rpm}$ for $60 \mathrm{~s}$. Postdeposition solvent vapour annealing was carried out by containing a raised as-cast substrate within a screw cap glass jar with $1 \mathrm{~mL}$ of THF in the bottom of the jar. Substrates were left exposed to the solvent vapour for 5 minutes. The substrates with the cast active layers were kept in an $\mathrm{N}_{2}$ atmosphere glovebox overnight before evaporating $\mathrm{MoO}_{3}$ and $\mathrm{Ag}$. The $10 \mathrm{~nm}$ of $\mathrm{MoO}_{3}$ followed by $100 \mathrm{~nm}$ of $\mathrm{Ag}$ were thermally deposited under vacuum (10-5 Torr). The active areas of the devices were $0.14 \mathrm{~cm}^{2}$. The current density-voltage $(\mathrm{J}-\mathrm{V})$ curves were measured by a Keithley 2420 source measure unit. The photocurrent was measured under AM 1.5 illumination at 100 $\mathrm{mW} / \mathrm{cm}^{2}$ under a Solar Simulator (Newport 92251A-1000). The standard silicon solar cell (Newport $91150 \mathrm{~V}$ ) was used to calibrate light intensity. All tests were carried out in air. 
Atomic Force Microscopy (AFM) Images:

Height

(A)

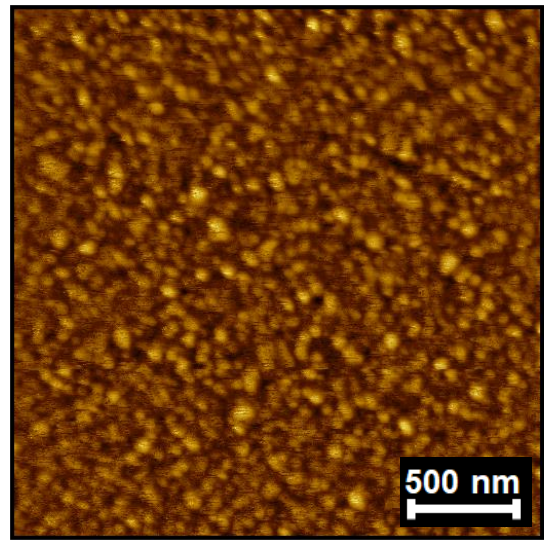

Phase

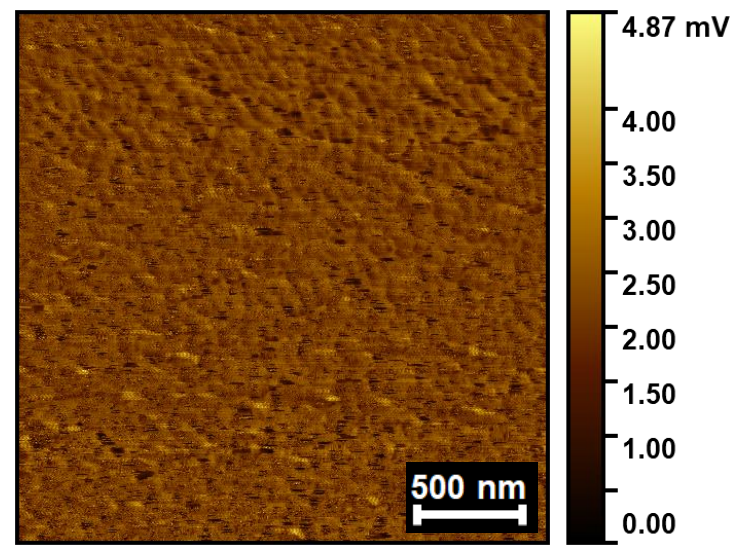

DPP-NPDI RMS $=1.6 \mathrm{~nm}$

(B)

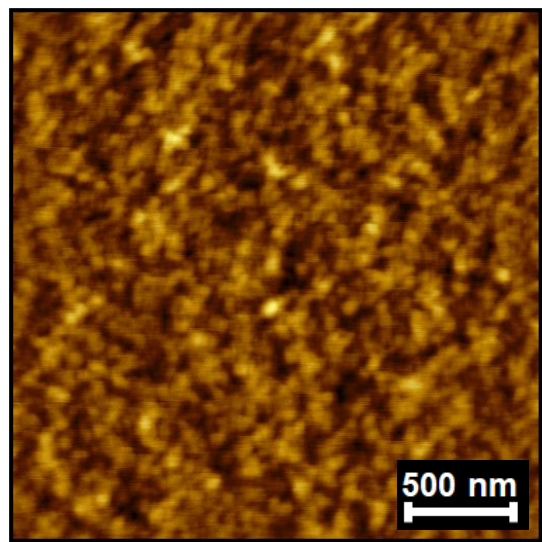

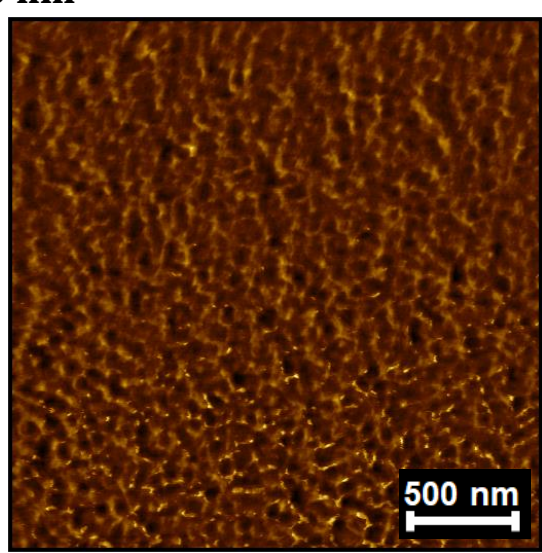

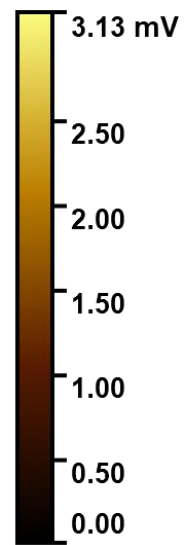

PTB7-Th:SePDI-DPP-NPDI (after THF SVA treatment)

$$
\text { RMS }=0.9 \mathrm{~nm}
$$

Figure S21. AFM height (left) and phase (right) images of OPV devices based on the PTB7Th:SePDI-DPP-NPDI active layer (3:7 blend ratio). (A) active layers as-cast. (B) active layers after a 5 min THF SVA treatment. 
Height

(A)
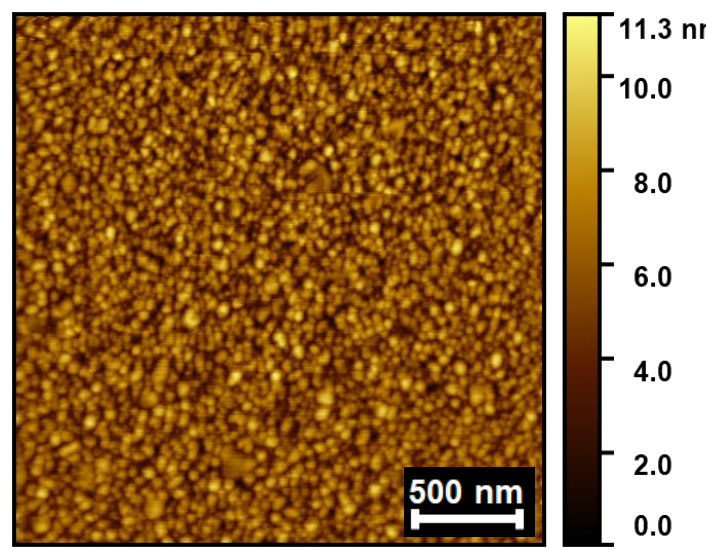

Phase

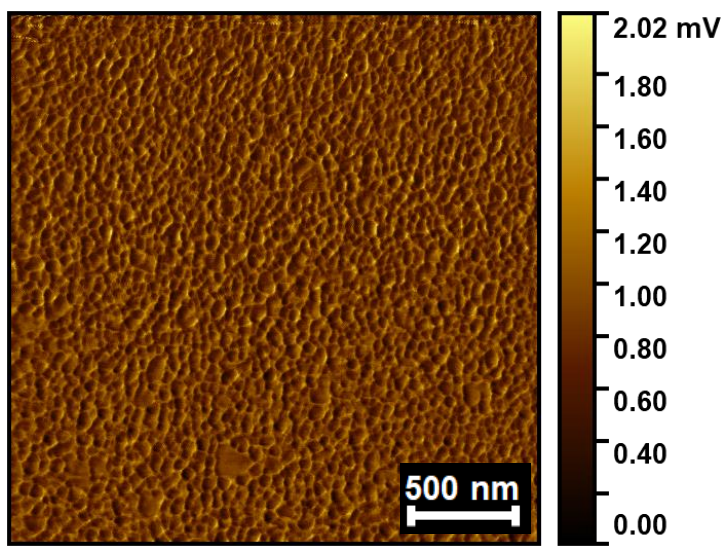

PTB7-Th: SePDI-DPP-SePDI RMS $=1.5 \mathrm{~nm}$

(B)
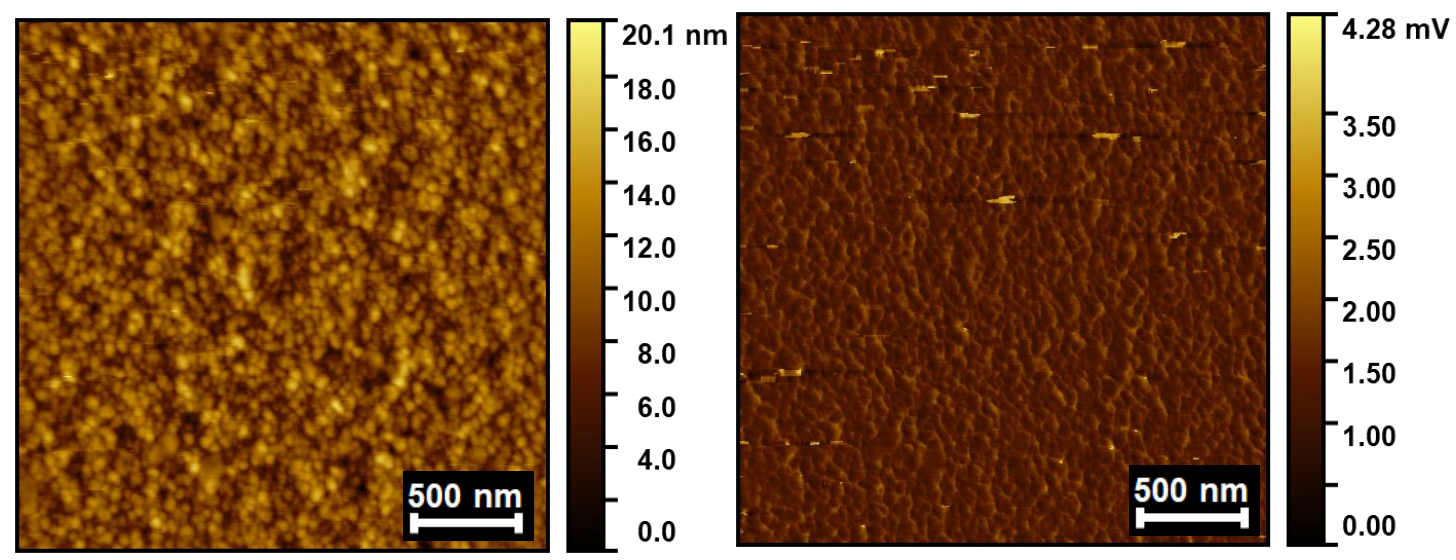

PTB7-Th: SePDI-DPP-SePDI (after THF SVA treatment) $\mathrm{RMS}=2.2 \mathrm{~nm}$

Figure S22. AFM height (left) and phase (right) images of OPV devices based on the PTB7Th:SePDI-DPP-SePDI active layer (3:7 blend ratio). (A) active layers as-cast. (B) active layers after a 5 min THF SVA treatment. 


\section{$\underline{\text { References }}$}

1 J. Pommerehne, H. Vestweber, W. Guss, R. F. Mahrt, H. Bässler, M. Porsch and J. Daub, Adv. Mater., 1995, 7, 551-554.

2Y. Sun, J. H. Seo, C. J. Takacs, J. Seifter and A. J. Heeger, Adv. Mater., 2011, 23, 1679-1683. 